\title{
Airway biomarkers of the oxidant burden in asthma and chronic obstructive pulmonary disease: Current and future perspectives
}

\author{
Noora Louhelainen' \\ Marjukka Myllärniemi' \\ Irfan Rahman² \\ Vuokko L Kinnula' \\ 'Department of Medicine, Division \\ of Pulmonary Medicine, University \\ of Helsinki and Helsinki University \\ Central Hospital, Helsinki, Finland; \\ ${ }^{2}$ Department of Environmental \\ Medicine and the Lung Biology and \\ Disease Program, University \\ of Rochester Medical Center, \\ Rochester, New York, USA
}

\begin{abstract}
The pathogenesis of asthma and chronic obstructive pulmonary disease (COPD) has been claimed to be attributable to increased systemic and local oxidative stress. Detection of the oxidant burden and evaluation of their progression and phenotypes by oxidant biomarkers have proved challenging and difficult. A large number of asthmatics are cigarette smokers and smoke itself contains oxidants complicating further the use of oxidant biomarkers. One of the most widely used oxidant markers in asthma is exhaled nitric oxide (NO), which plays an important role in the pathogenesis of asthma and disease monitoring. Another oxidant marker that has been widely investigated in COPD is 8-isoprostane, but it is probably not capable of differentiating asthma from COPD, or even sensitive in the early assessment of these diseases. None of the current biomarkers have been shown to be better than exhaled NO in asthma. There is a need to identify new biomarkers for obstructive airway diseases, especially their differential diagnosis. A comprehensive evaluation of oxidant markers and their combinations will be presented in this review. In brief, it seems that additional analyses utilizing powerful tools such as genomics, metabolomics, lipidomics, and proteomics will be required to improve the specificity and sensitivity of the next generation of biomarkers.
\end{abstract}

Keywords: sputum, condensate, smoking, nitric oxide, 8-isoprostane, biomarker

Asthma and chronic obstructive pulmonary disease (COPD) are diseases with different physiological and anatomical features. However, a significant number of patients suffering from these diseases exhibit symptoms and signs which are associated with both conditions. Markers of the elevated oxidant burden have been detected in both of these disorders. This degree of overlap between asthma and COPD has proved to be especially important in smoking asthmatics, patients who have often been excluded from asthma trials and investigations. Oxidant markers are under intensive investigation as ways of assuring the early detection and monitoring of asthma and COPD, for the differentiation of the disease from the condition of "healthy smokers", and also for the evaluation of the COPD phenotypes and their progression. This review will critically review potential markers that reflect oxidative stress in the airways of patients with asthma and COPD in exhaled air, exhaled breath condensate (EBC) and induced sputum. In addition, markers in bronchoalveolar lavage (BAL) will also be briefly surveyed, even though the technique, ie, fibreoptic bronchoscopy is an invasive technique used in the investigation of lung inflammation and the evaluation of the oxidant burden. In this review, we will also discuss the pros and cons of various noninvasive biological samples for assessing the oxidant burden in the airways, and then speculate on the possibilities of using the existing and new oxidant markers, 
their potential combinations, and make suggestions for future investigations.

\section{Clinical and inflammatory features of asthma and COPD}

According to the Global Initiative for Asthma Guidelines (GINA 2002) asthma is defined as a chronic inflammatory disorder of the airways in which many cells and cellular elements play a role. The chronic inflammation evokes an associated increase in airway hyperresponsiveness that leads to recurrent episodes of wheezing, breathlessness, chest tightness, and coughing, particularly at night or in the early morning. These episodes are usually associated with widespread but variable airflow obstruction that is often reversible, either spontaneously or with treatment. In the Global Initiative for Chronic Obstructive Lung Disease Guidelines (GOLD 2002; Rabe et al 2007), COPD is defined as a preventable and treatable disease state characterized by airflow limitation that is not fully reversible. COPD is also associated with emphysematous parenchymal destruction, variable loss of lung elastic recoil, and abnormalities in gas diffusion. The physiological findings in individual patients with either clinical asthma or COPD, when isolated from the context of their environmental and clinical histories, may not allow the physician to distinguish between the conditions (Boulet et al 1998; Fabbri et al 2003). This inability to clearly differentiate these conditions can lead to frustration in both the clinic and research settings.

There are a large number of studies and reviews on the inflammatory profile in asthma and COPD (Kirby et al 1987; Walters and Gardiner 1992; Keatings and Barnes 1997; Chanez et al 1999; van Aalderen et al 1999; Gibson et al 1999; Jeffery 1999; Saetta 1999; NHLBI/WHO 2002; Loh et al 2005; Tetley 2005). Airway inflammation is present in all forms of asthma, even in mild (Battaglia et al 2005) and asymptomatic cases (Bousquet et al 2000; Montuschi et al 2004) and it can be detected in both central and peripheral airways (Hamid et al 1997) in asthma. There is a strong association between fractional exhaled nitric oxide (FeNO) and skin prick test scores, total immunoglobulin E (IgE) (Ho et al 2000) and blood eosinophilia (Silvestri et al 1999). In contrast, COPD is a disease characterized by airway inflammation with neutrophil predominance (Bosken et al 1992), and periods of acute exacerbations (Fletcher and Peto 1977) with further increased airway inflammation and worsening of lung function (Gompertz et al 2001). Cigarette smoking is the major risk factor for development of COPD, and smoking cessation is at present the only effective way to slow down the disease progression (Culpitt and Rogers 2000; Scanlon et al 2000). COPD exacerbations are often triggered by viral or bacterial infections consisting not only of increased numbers of neutrophils, but also of eosinophils and activated macrophages in the airways (Rahman and MacNee 2000; Saetta et al 2001). Neutrophil accumulation on the other hand is one typical feature that is seen in asthma exacerbation (Fahy et al 1995a; Kim et al 2000). There is overlap not only in the inflammatory profile but also in the oxidant markers, especially in acute asthma and COPD exacerbations. The present review focuses on oxidant markers, but the numbers of certain inflammatory cells and the levels of cytokines have also been found to be significantly correlated with oxidant markers in the airways of patients with asthma and COPD.

The differential diagnosis of asthma and COPD is especially difficult in smoking individuals. Cigarette smoke activates macrophages and polymorphonuclear leukocytes to produce more reactive oxygen species (ROS) and this, in turn, leads to the recruitment of leukocytes into the airways (Niewoehner et al 1974; Hoidal and Niewoehner 1982). Since symptoms and lung function tests are indirect methods to assess the disease severity both in asthma and COPD, they may not reveal the extent of the underlying airway pathology. Smoking alone has multiple effects on the airways and there is a need to clearly differentiate the effects of smoking from the disease and its progression, a topic that has not been systematically evaluated.

\section{Biomarker requirements in asthma and COPD differentiation}

Oxidative stress has been claimed to be involved in the development of both asthma and COPD (Kharitonov and Barnes 2001b; Montuschi et al 2004; Kinnula 2005a; Rahman and Adcock 2006). There is more than one phenotype in COPD and asthma and these phenotype subtypes have not been separately evaluated with respect to the profiles of the oxidative stress burden are influenced in the different phenotypes. Currently, there is plenty of research being conducted to develop noninvasive tools for disease detection and follow-up, eg, easy-to-use devices and sensitive and specific technologies. Only practical and readily reproducible, completely noninvasive techniques offer these possibilities. The biomarkers themselves must possess certain characteristics if they are to be of any use. In addition to sensitivity and specificity, a biomarker needs to be stable, with minimal diurnal or day-to-day variability, and it should be easy to access and analyse, and still be cost-effective. Furthermore, the biomarkers should be 
useful for early diagnostics, differential diagnosis, response to therapy, and for the evaluation of disease progression. It is unlikely that any single biomarker can ever possess all these characteristics. Instead, panels or various combinations of biomarkers are needed. These panels could consist of different components if they are used for either the differential diagnosis or for the assessment of disease severity and its progression.

\section{Oxidative stress in the airways in asthma and COPD}

ROS and reactive nitrogen species (RNS) are produced endogenously by several cell types including activated inflammatory and structural cells, the most potent generators of these species being eosinophils and neutrophils, ie, cells that are abundant both in asthma and COPD (Kinnula 2005b). The burden of ROS/RNS is further increased by exogenous factors, mostly by environmental agents and cigarette smoke. One puff of cigarette smoke contains billions of free radicals (Church and Pryor 1985). These ROS, present both in asthma and smoking-related airway diseases, have multiple effects including activation of proteases, mucus secretion, airway smooth muscle contraction, airway hyperresponsiveness, and transcription of many inflammatory genes (Kawikova et al 1996; Rahman and MacNee 1998; Paredi et al 2002; Wood et al 2003).

Oxidants present in cigarette smoke stimulate alveolar macrophages to further produce ROS, such as superoxide radical $\left(\mathrm{O}_{2}^{\cdot-}\right)$, hydroxyl radical $\left({ }^{\circ} \mathrm{OH}\right)$, and hydrogen peroxide $\left(\mathrm{H}_{2} \mathrm{O}_{2}\right)$, leading to release of a number of mediators, some of which attract neutrophils and other inflammatory cells into the lungs of COPD patients (GOLD 2002). Activated inflammatory cells generate more ROS via the NADPH oxidase system. Similarly, increased levels of xanthine oxidase, found in cell free bronchoalveolar lavage (BAL) fluid and plasma from COPD patients, can elevate $\mathrm{O}_{2}{ }^{\cdot-}$ and lipid peroxide levels (GOLD 2002). Thus, oxidants may be triggering factors for the inflammation seen in COPD. Asthma on the other hand, may be triggered by viral infections, air pollutants such as ozone and cigarette smoke, and other cellular mediators (Dworski 2000). These agents cause influx and activation of inflammatory cells (macrophages, neutrophils, eosinophils, lymphocytes, and mast cells) which subsequently evoke the generation of inflammatory mediators. All of these converge to produce ROS which in turn leads to an increased inflammatory response, producing asthma-like symptoms. Oxidative stress is associated with activation of cytokines/growth factors but in these same conditions activated inflammatory cells produce large amounts of ROS into the airways. Thereby it can be postulated that symptoms are not only linked to the airway inflammation but also to the oxidant burden in the airways both in asthma and COPD. ROS have been shown to be associated with the pathogenesis of asthma by evoking bronchial hyperreactivity as well as directly stimulating histamine release from mast cells and mucus secretion from airway epithelial cells (Dworski 2000). Thus, while oxidative stress due to smoking is a direct causative factor for COPD leading to a further elevation of oxidative stress, it is usually a secondary effect in asthma subsequent to a prior antigenic/allergic challenge of immune cells in the lungs.

Once oxidative stress reaches a critical level, it is difficult to demarcate between the two diseases asthma and COPD. However, site of affliction, the cells involved and the pattern of response by the lungs can help in differentiating these two diseases. In COPD, the major site of attack is the alveolar space. Inflammatory cells themselves become compartmentalized, for example, neutrophils are mainly located in the lumen of the airways and macrophages accumulate in the interstitium in COPD. COPD has been strongly associated with an accumulation of inflammatory mucous exudates in the lumen of the small airways (Saetta et al 2001). In COPD, oxidant stress occurs in small airways, lung parenchyma, and the alveolar regions. In asthma, the larger airways are the major site of action, with the characteristic signs being reversible airflow obstruction, airway hyper-responsiveness/hyperreactivity, and chronic inflammation attributable to an influx of eosinophils and activation of inflammatory cells such as macrophages, neutrophils, lymphocytes, and mast cells. Airway smooth muscle contraction, increased airway reactivity and secretions, increased vascular permeability and increased generation of chemoattractants are the major features of an asthmatic response (Hamid et al 1997). Hence, compartmentation of different inflammatory cells in the lungs may help clarify the type of oxidative stress response in asthma and COPD.

Many oxidants (such as $\mathrm{O}_{2}^{\cdot-}$ and ${ }^{\circ} \mathrm{OH}$ ) are unstable and have very short half lives, and are therefore difficult to measure. Hydrogen peroxide $\left(\mathrm{H}_{2} \mathrm{O}_{2}\right)$ is formed from superoxide (mainly by inflammatory cells including both eosinophils and neutrophils) and is directly involved in many reactions. NADPH oxidase is one of the key superoxide generating enzymes that is expressed both in phagocytic and nonphagocytic cells (Jones et al 2000). NADPH oxidases (NOXs) and dual oxidases (DUOXs) may function as potent ROS generators in inflammatory conditions of human airways, but little is known about their role in asthma or COPD. Myeloperoxidase 
(MPO) is abundantly present in neutrophils and catalyses the reaction of $\mathrm{H}_{2} \mathrm{O}_{2}$ with chloride forming hypochlorous acid $(\mathrm{HOCl})$. Eosinophil peroxidase (EPO) catalyses the reaction of $\mathrm{H}_{2} \mathrm{O}_{2}$ with bromide within eosinophils forming hypobromous acid ( $\mathrm{HOBr})$, which is released during the respiratory burst (Wu et al 2000; van Dalen and Kettle 2001; Aldridge et al 2002). Endogenous NO is derived from L-arginine by at least three different isoforms of NOS (Nathan and Xie 1994). Two of these are expressed constitutively (NOS1, NOS3) while the inducible form of NOS (iNOS, NOS2) can be activated by inflammatory cytokines. Inducible NOS generates the majority of the NO encountered in inflammatory states since the enzyme is induced by cytokines and is expressed in inflammatory cells (like neutrophils) as well as in nonphagocytic cells (like alveolar/bronchial epithelial and endothelial cells) (Barnes and Belvisi 1993). Once ROS are generated, they rapidly attack membrane lipids leading to the generation of lipid peroxidation products such as isoprostanoids, malondialdehyde, and 4-hydroxy-2-nonenal (4-HNE). These markers have been widely used in the assessment of oxidative stress in the lung (Kharitonov and Barnes 2001b; Paredi et al 2002), but a major limitation with most of these end products is their poor specificity and reproducibility in different diseases that are related to oxidative stress. Each of these markers will be discussed below in the context of their use in asthma and COPD diagnosis and differentiation.

The antioxidant machinery of the lung is complex, containing a variety of low molecular weight antioxidants, metal binding proteins, mucus glycoproteins, and several specific antioxidant enzymes (Kinnula et al 1995; Kinnula and Crapo 2003; Kinnula 2005a, 2005b). It is apparent that in oxidant-mediated airway diseases, ROS gradually overwhelm host antioxidant defenses, leading to the ultimate oxidant-mediated cell and tissue damage (Kinnula 2005b). Total antioxidant capacity of plasma is decreased in smokers and patients with asthma and COPD (Rahman et al 1996). It is interesting to note that the decrease in antioxidant capacity in smokers occurs transiently during smoking and resolves rapidly after smoking cessation. The depletion of total antioxidant capacity in smokers is associated with decreased levels of plasma antioxidants eg, ascorbic acid, vitamin E, $\beta$-carotene, and selenium (Rahman et al 1996). The depletion of antioxidants may thus be a reflection of ongoing oxidative stress due to underlying inflammation in these diseases. The thiol antioxidant glutathione (GSH) and its key biosynthesizing enzyme, glutamate cysteine ligase (GCL), are decreased in the airways, and in macrophages of smokers compared to nonsmokers (Harju et al 2002a). However, very little is known about antioxidant enzymes/antioxidant biomarkers in asthma and COPD or their association with disease severity or progression. It is likely that there are no specific changes in the antioxidant systems during the early phases of airway diseases, instead their changes may reflect disease severity.

\section{Noninvasive techniques to detect airway oxidative stress: Pros and cons \\ Exhaled air}

Even though several methods have been developed to measure oxidant related damage/burden in cells, tissues, and body fluids, there has been great interest in the analysis of exhaled air since this is a totally noninvasive technique. Standardized measurements of fractional exhaled nitric oxide (FeNO) provide a noninvasive and reproducible means for monitoring asthma (Kharitonov et al 1997; Anonymous 1999; Kharitonov 2004). A wide range of commercially available analyzers exist, which decreases the cost of individual measurements. Persistent generation of oxygen radicals in the body leads to the formation of other compounds, which can also be measured from the exhaled air; these include carbon monoxide (CO) which is formed by enzymatic degradation of heme and nonheme-related release (Kharitonov and Barnes 2001b) and hydrocarbons such as volatile organic compounds (VOC), which are nonspecific markers of lipid peroxidation (Kneepkens et al 1994). The activation of inflammatory cells, including macrophages, eosinophils, and neutrophils, results in increased production of $\mathrm{O}_{2}{ }^{--}$and the subsequent formation of $\mathrm{H}_{2} \mathrm{O}_{2} \cdot \mathrm{H}_{2} \mathrm{O}_{2}$ has been proposed to be a potential marker of oxidative stress in the lungs and this mediator has been evaluated in many investigations (Kharitonov 2004). In summary, exhaled air is one of the most promising ways for the assessment of oxidative stress; it has many advantages and the technology is now being developed so that there are portable devices at a relatively low cost. There exists, in addition, a good consensus on the significance of some oxidant markers (such as FeNO) that are detectable from the exhaled air.

\section{Exhaled breath condensate}

Exhaled breath condensate (EBC) is condensed from water but also contains droplets that carry solute from the lower respiratory tract. The collection of EBC by cooling exhaled air has several advantages compared to many other methods of sampling the airspaces. It is simple to conduct, noninvasive, and easily repeatable (Kharitonov and 
Barnes 2001b). It does not cause airway inflammation, nor does it have any significant influence on airway function (Baraldi et al 2003c), making repeated sampling possible (Kharitonov and Barnes 2001b; Kharitonov and Barnes 2002). EBC collection is relatively inexpensive and does not include any appreciable discomfort or risk to the subject. Moreover, EBC collection is also suitable for children, because it is effort-independent. It can even be applied in mechanically ventilated patients. The collection of EBC has been described in detail (Rahman and Biswas 2004; Horvath et al 2005). Many nonvolatile molecules (mediators, oxidation, and nitration products) can be measured in EBC, with 8-isoprostane being the most widely measured of the oxidant markers found in EBC (Kharitonov and Barnes 2001b). There is accumulating evidence suggesting that the abnormalities in biomarkers present in EBC may reflect the degree of asthma and COPD severity better than can be assessed by either spirometry or symptoms (Montuschi et al 1999; Kharitonov and Barnes 2001b).

EBC mirrors the composition of the extracellular lining fluid (ELF) but the major drawbacks are saliva contamination, sample dilution, and high individual variability. There exists a lack of evidence of the primary origin of the aerosol particles that carry the droplets from the lower respiratory tract (Van Hoydonck et al 2004). Dilution of EBC can be corrected by measuring the level of urea and/or electrolytes derived from ELF. Other confounding factors include consumption of alcohol, diets with variable amounts of antioxidants, smoking, subclinical lung diseases which have not been clinically manifested, and differences in the collection of the samples and their storage. Significant salivary contamination can be excluded by measuring the amylase concentrations in samples (Kharitonov and Barnes 2001b), but uncertainty still exists with respect to the nasal contamination. Recommendations for EBC have been formulated by the European Respiratory Society/American Thoracic Society task force, but these recommendations also emphasized the difficulties encountered in the sampling and analysis of EBC (Horvath et al 2005). To date the majority of the analyses conducted in EBC have involved spectrophotometry and enzyme immunoassays, as well as sophisticated analytical techniques such as gas chromatography/mass spectrometry (GC/MS) or high-performance liquid chromatography (HPLC). Spin trapping is one of the most direct methods available for the assessment of highly reactive free radicals/oxidants. These latter techniques require special expertise and as far as we are aware, they have not been used for assaying EBC in clinical settings. In summary, the collection of EBC is easy and it is therefore promising for the evaluation of oxidant markers. Major limitations in the EBC include the plethora of potential markers that cannot be reliably or easily analyzed in these highly diluted samples.

\section{Induced sputum}

Induced sputum represents a nearly noninvasive technique; the collection of induced sputum by hypertonic saline has been shown to be a safe (Vlachos-Mayer et al 2000; Wark et al 2001), effective, and relatively reproducible (Pizzichini et al 1996; Ward et al 1999; Fahy et al 2001; Simpson et al 2005) method for investigating airway diseases in adults (Pizzichini et al 1998; Wark et al 2002; Wilson et al 2006) and children over 6 years of age (Twaddell et al 1996; Norzila et al 2000). Induced sputum samples provide information about both inflammatory mediators and the inflammatory cells present in the airways (Simpson et al 2005) and they are believed to accurately mirror conditions at the site of oxidative damage (Kelly et al 1999).

However, there is some evidence that induced sputum is sampled predominantly from the large airways (Alexis et al 2001) and may not reflect the peripheral airways. Sputum induction is often difficult to accomplish, involves some discomfort to the patient, induces an inflammatory response (Nightingale et al 1998), and may induce coughing and bronchoconstriction in patients with COPD (Rytila et al 2000; Taube et al 2001) and in asthma (Smith and Anderson 1990; Antczak et al 2005), despite pretreatment with an inhaled beta2-agonist (Rytila et al 2000; Paggiaro et al 2002). The processing of the sputum sample needs to be immediate and requires expertise and this significantly limits its use in routine clinical practice. Sampling cannot be repeated within a short period of time, and the technique itself may induce an inflammatory response, which may persist for $24 \mathrm{~h}$ (Nightingale et al 1998; Holz et al 1998). Contamination of sputum samples by saliva may lead to reduced mediator concentrations, although differential cell counts remain relatively unchanged (Simpson et al 2004). On the other hand, several markers are relatively similar in the induced sputum and BAL and the technique of collecting induced sputum is much less invasive than fibreoptic bronchoscopy (Fahy et al 1995b). Overall, induced sputum is a standardized method and recommendations for sputum induction have been formulated by a European Respiratory Society/American Thoracic Society task force (Djukanovic et al 2002). Induced sputum and its processing do require expertise that may be available in specialized centers though its use in a primary care setting would be demanding. 


\section{Bronchoalveolar lavage (BAL)}

Bronchoalveolar lavage has the advantage of sampling the distal airways and alveoli in the lung periphery (Kelly et al 1987). However, BAL is more invasive than the above-mentioned procedures and has also several other limitations. The invasiveness of BAL limits its clinical application in assessing airway inflammation in asthma and COPD. Generally, BAL has been performed safely on patients with stable COPD (Hattotuwa et al 2002). BAL is, however, risky to patients with moderate/severe lung disease, acute exacerbations of airway disease and also is unsuitable for children. It is also associated with sedation, impaired gas exchange and a risk of infections. Even though the BAL technique has also been standardized (Haslam and Baughman 1999), BAL fluid of COPD patients is often inadequate and not representative of the situation in the bronchioles due to airway collapse and reduced fluid recovery (Barnes et al 2006). Saline instillation into the lungs can lead to artefacts, ie, the dilution of the lavage may contribute to the variability of measurements. BAL cannot be recommended for the diagnosis or follow-up of the patients with asthma or COPD.

\section{Exhaled markers of oxidant burden in asthma and COPD}

The markers of oxidant burden that have been generally measured from the human lung are shown in Figure 1.

\section{Exhaled nitric oxide metabolites}

Elevated FeNO levels have been widely documented in adults (Kharitonov et al 1994; Persson et al 1994) and children (Lundberg et al 1996; Byrnes et al 1997; Nelson et al 1997) with asthma, even in mild and asymptomatic conditions (Alving et al 1993; Kharitonov and Barnes 2001b). FeNO levels correlate with eosinophilic airway inflammation and predict a decline in asthma control when repeated as longitudinal measurements (Kharitonov and Barnes 2001a; Liu and Thomas 2005; Smith et al 2005). The changes in serial FeNO have a higher predictive value than single measurements (Jatakanon et al 2000; Leuppi et al 2001; Kharitonov and Barnes 2001a). In addition, the level of FeNO is related to several markers of asthma control, such as asthma symptoms, dyspnea score, daily use of rescue medication, and reversibility of airflow obstruction (Sippel et al 2000). Elevated FeNO levels can be detected before one can determine any significant deterioration in airway hyperresponsiveness, elevation of sputum eosinophil levels or changes in lung function parameters (Kharitonov et al 1996b; Jatakanon et al 2000). The main site of origin of the increased levels of FeNO in asthma is the lower airways (Kharitonov et al 1996a). The measurement is highly reproducible both in healthy and asthmatic adults and children (Kharitonov et al 2003). Measurements of exhaled NO at different flows show

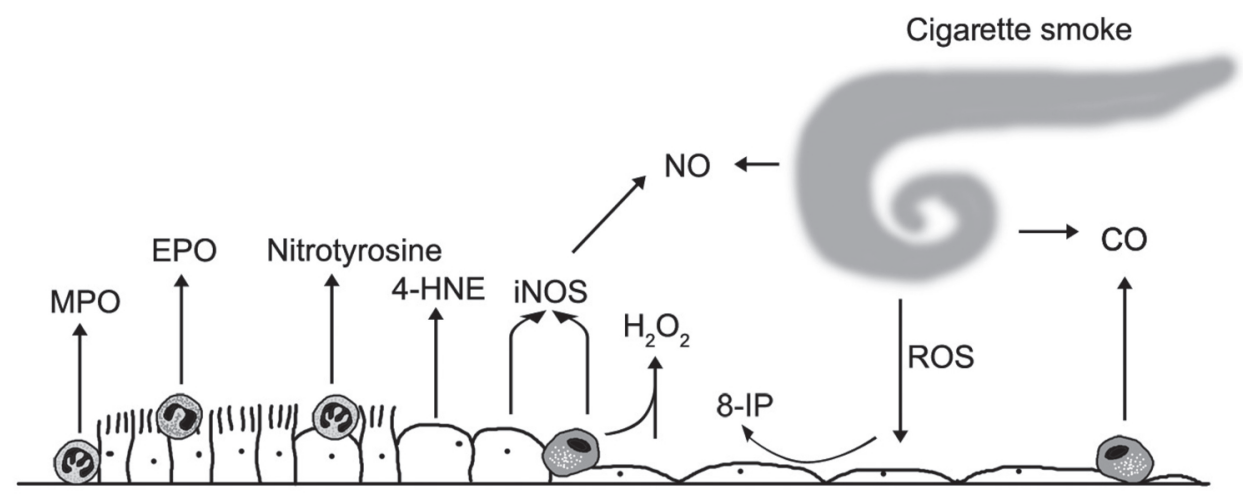

\footnotetext{
(2) Eosinophilic granulocyte

(b) Neutrophilic granulocyte

(2.) Macrophage
}

Figure I The markers of oxidative stress are derived from different cells and cell compartments in the alveolar or bronchiolar wall. Neutrophilic granulocytes express myeloperoxidase (MPO) and eosinophilic granulocytes are endowed with eosinophilic peroxidase (EPO). Inducible nitric oxide synthase (iNOS) is expressed in the inflammatory

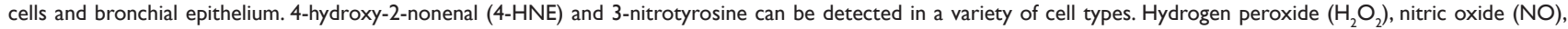
carbon monoxide (CO), and 8-isoprostane (8-iso) represent widely investigated markers in the exhaled air/exhaled breath condensate. 
that the increase in peripheral $\mathrm{NO}$ is often related to disease severity (Brindicci et al 2005). Overall FeNO is one of the most widely used biomarkers in the diagnosis of asthma especially when the diagnosis is uncertain; recent results clearly highlight its benefits also in asthma management.

Exhaled NO is, however, somewhat nonspecific, for example the levels are increased in viral infections (Kharitonov and Barnes 2001b). On the other hand, FeNO levels are generally decreased in smokers (Maziak et al 1998; Rytila et al 2006). There is also some disagreement on whether changes in serial FeNO are significant evidence of loss of asthma control or simply due to errors in measurements or the natural variability of airway inflammation over time (Kharitonov 2004). This suggests that FeNO may not always be related to asthma severity or airway inflammation (Kharitonov and Barnes 2000). Development of less expensive FeNO analyzers would be beneficial, since for now FeNO analyzers are available mostly in central/university hospitals. Despite these problems, FeNO measurements have remained as one of the most important parameters in evaluating, treating, and monitoring patients with asthma and airway disease with eosinophilic inflammation.

In contrast to asthma, the FeNO levels in stable COPD do not differ significantly from controls (Kharitonov and Barnes 2001b; Rytila et al 2006). FeNO levels increase during COPD exacerbation (Maziak et al 1998), most likely due to increased oxidative stress especially in cases with coexistent asthma and/or the presence of airway eosinophils (Papi et al 2000). The elevated levels of FeNO in unstable COPD compared both with stable smokers or ex-smokers with COPD are attributable to the presence of eosinophils (Maziak et al 1998). On the other hand, cigarette smoke decreases FeNO levels (Kharitonov et al 1995; Robbins et al 1996) by downregulating eNOS (Su et al 1998) and consuming NO, making FeNO an unreliable marker for the diagnosis of asthma in smokers. FeNO has a minor role in evaluating COPD, but it may have importance in the differentiation of asthma, eosinophilic bronchitis, and COPD.

The reaction of $\mathrm{NO}$ and $\mathrm{O}_{2}{ }^{--}$in the airways leads to the formation of peroxynitrite (ONOO) which reacts with tyrosine residues of proteins to form a stable product, nitrotyrosine. Nitrotyrosine can be detected in EBC, its levels are increased in asthma and decreased by corticosteroid treatment (Hanazawa et al 2000; Baraldi et al 2006; Bodini et al 2006). However, even though both HPLC and GC/MS measurements are sensitive and detect similar nitrotyrosine levels in the EBC, they do not differentiate healthy controls from asthmatics, and therefore nitrotyrosine does not seem to be a selective marker for oxidative stress in asthma (Celio et al 2006).

Nitric oxide can be trapped by thiol-containing biomolecules (such as GSH) to form S-nitrosothiols. The levels of these compounds are elevated in the EBC of smokers and in patients with asthma (Corradi et al 2001) and the levels decline with corticosteroid treatment in asthma (Kharitonov et al 2002). Overall, the increase of the S-nitrosothiols in EBC is transitory, and probably not sensitive enough to help in the diagnostic assessment of airway diseases. Moreover, the levels of $\mathrm{NO}(\mathrm{x})$ in $\mathrm{EBC}$ appear to be too variable to be beneficial in clinical investigations (Franklin et al 2006).

\section{Volatile organic compounds}

There are many volatile hydrocarbons, but only a few of them have been analyzed from exhaled air, with the most widely investigated being ethane. Elevated exhaled ethane levels have been detected in patients with mild steroid-naïve asthma compared with steroid-treated patients and normal subjects (Paredi et al 2000a). COPD patients display elevated exhaled ethane levels that correlate with the degree of airway obstruction (Paredi et al 2000b). Exhaled ethane, however, is increased by physical (Leaf et al 1997) and mental stress and smoking (Habib et al 1995), probably due to the high concentrations of hydrocarbons and direct oxidative damage. Cigarette smoke itself contains ethane, and a transient elevation of exhaled ethane has also been detected in healthy smokers (Habib et al 1995). Another hydrocarbon of clinical interest is n-pentane and there are some correlations between breath pentane and serum biomarkers in smokers. Ethane is easier and faster to measure by GC/MS than the other hydrocarbons, but nonetheless these assays are difficult to conduct as the analyses require expertise, their measurement is expensive, and the biomarker itself is not specific for any particular airway disease. Moreover primary health care centers may not have access to a gas chromatograph or the necessary skills inherent in this technique. In brief, the measurement of ethane is demanding and difficult to transfer to clinical practice (Larstad et al 2002; Barnes et al 2006). Moreover, aldehydes can be detected both in EBC and induced sputum but their relative concentrations are different and do not correlate with each other (Corradi et al 2004). There are a number of other VOCs in addition to ethane; whether their combination, ie, VOC "profiles" can be developed to be assayed by modern small gas chromatographic techniques would be an interesting area for future research. Recently, one technique, so called the electronic nose, in which expiratory vital capacity is collected and then smellprints are 
analyzed by linear discriminant analysis, has been found to be a promising method in differentiating exhaled breath of patients with asthma from controls even though it appears to be less accurate in distinguishing the severity of asthma (Dragonieri et al 2007).

\section{Carbon monoxide}

Carbon monoxide (CO) is derived from the degradation of heme by hemeoxygenase or nonheme-related release from xenobiotics and bacteria. Approximately $85 \%$ of $\mathrm{CO}$ is exhaled (Kharitonov and Barnes 2001b; Barnes et al 2006). Many pathological conditions in addition to airway inflammation, can contribute to $\mathrm{CO}$ formation. One major limitation of exhaled $\mathrm{CO}$ in assessing oxidative stress in asthma or COPD is the marked effects of smoking on $\mathrm{CO}$ concentrations. The levels of exhaled $\mathrm{CO}$ are elevated in stable asthma and become reduced towards the normal values by administration of inhaled corticosteroids (Zayasu et al 1997; Horvath et al 1998; Barnes et al 2006). The effects of smoking make the assessment of exhaled CO in COPD difficult. Exhaled $\mathrm{CO}$ can be measured by electrochemical sensors, laser spectrophotometry, and by an infrared CO analysis as well as by gas chromatography, methods that are widely available in clinical laboratories. The analysis of $\mathrm{CO}$ is straightforward but the levels of $\mathrm{CO}$ are too variable to be significant in the clinical assessment of asthma and COPD, their diagnosis, or follow-up.

\section{Hydrogen peroxide}

Exhaled $\mathrm{H}_{2} \mathrm{O}_{2}$ has been detected in steroid-naïve asthmatics (Kharitonov and Barnes 2002), patients with stable COPD and during COPD exacerbation (Dekhuijzen et al 1996; Kharitonov 2004) being associated with the disease severity (Kostikas et al 2003). Macrophages from healthy smokers release more $\mathrm{H}_{2} \mathrm{O}_{2}$ than the cells from nonsmokers (Baughman et al 1986; Nowak et al 1996; Guatura et al 2000). Exhaled $\mathrm{H}_{2} \mathrm{O}_{2}$ concentrations are higher in smoking than nonsmoking asthmatic patients or controls, though there is extensive variability (Horvath et al 2004). Acute smoking leads to a further elevation in exhaled $\mathrm{H}_{2} \mathrm{O}_{2}$ levels in asthmatic patients indicating that smoking causes an acute additional release of ROS in the airways (Horvath et al 2004). Since $\mathrm{H}_{2} \mathrm{O}_{2}$ evaporates readily due to its highly unstable nature and its concentration decreases after a few days of storage at $-70{ }^{\circ} \mathrm{C}$, it needs to be assayed immediately (van Beurden et al 2002). One study claimed that $\mathrm{EBC}$ can be stored for up to 40 days without any loss of $\mathrm{H}_{2} \mathrm{O}_{2}$ concentration (van Beurden et al 2002). However, the variability of the $\mathrm{H}_{2} \mathrm{O}_{2}$ levels in airway fluids is high, generally the levels of $\mathrm{H}_{2} \mathrm{O}_{2}$ are low and the methods for $\mathrm{H}_{2} \mathrm{O}_{2}$ analysis are insensitive (Van Hoydonck et al 2004). There are different techniques, all with their own limitations for $\mathrm{H}_{2} \mathrm{O}_{2}$ detection and therefore meaningful comparison of the results from various laboratories is difficult (Van Hoydonck et al 2004). In summary, $\mathrm{H}_{2} \mathrm{O}_{2}$ is released from a number of cell types, it is relatively unstable, and its analysis is not sufficiently sensitive or specific to allow the diagnosis, differential diagnosis, or monitoring of asthma or COPD.

\section{8-isoprostane}

Oxidative damage to lipids leads to the production of isoprostanes, which are prostaglandin analogues produced primarily by free radical-induced peroxidation of arachidonic acid (Morrow et al 1990). 8-iso-prostaglandin $\mathrm{F}_{2 \alpha}$ (8-isoprostane) is the best-characterized isomer, and is considered to be a reliable index reflecting the degree of oxidative stress in vivo. It is a stable metabolite and specific to lipid peroxidation (Janssen 2001; Morrow and Roberts 2002; Cracowski et al 2002). It has been proposed to represent an important tool for reliably exploring oxidative stress in lung diseases (Montuschi et al 2004). Moreover, dietary fats do not have any significant effect on the 8-isoprostane concentration (Gopaul et al 2000). Although antioxidants scavenge ROS, it seems that they fail to reduce the rate of lipid peroxidation (Anderson et al 1988; Habib et al 1999) possibly due to the fact that lipid peroxidation is the result of a complicated metabolic pathway, where only the first step is initiated by free radicals (Morrow et al 1990). Nevertheless several studies have indicated that 8-isoprostane may be an important mediator of oxidative stress and pulmonary oxygen toxicity (Janssen 2001) and form part of a common pathway leading to airflow obstruction (Paredi et al 2002).

Most studies have used commercial EIA (enzyme immunoassay) kits to detect 8-isoprostane in EBC, this technique has a good correlation with GC/MS (Montuschi et al 1999, 2000; Antczak et al 2002; Kostikas et al 2003; Biernacki et al 2003; Baraldi et al 2003a; Van Hoydonck et al 2004; Battaglia et al 2005; Simpson et al 2005), though there are also dissenting voices (Van Hoydonck et al 2004; Rahman 2004; Bodini et al 2004; Simpson et al 2005). Elevated EBC 8-isoprostane concentrations have been reported in children (Baraldi et al 2003a, 2003b; Mondino et al 2004; Shahid et al 2005) and adults with asthma (Montuschi et al 1999; Antczak et al 2002; Battaglia et al 2005) and COPD (Montuschi et al 2000; Kostikas et al 2003; Biernacki et al 2003; Ko et al 2006). The concentrations increase with asthma severity 
(Montuschi et al 1999; Kharitonov and Barnes 2001b) and decline following resolution of acute asthma exacerbations, though they still remain higher than in healthy individuals (Baraldi et al 2003a). EBC 8-isoprostane concentrations decline after allergen avoidance in children with allergic asthma (Bodini et al 2004), but are relatively resistant to inhaled corticosteroid therapy (Montuschi et al 1999; Baraldi et al 2003a, 2003b; Mondino et al 2004; Shahid et al 2005). The levels do not correlate with FeNO (Baraldi et al 2003a) or lung function parameters in children with asthma (Baraldi et al 2003b; Shahid et al 2005). The levels of 8-isoprostane are increased in EBC of COPD irrespective of smoking status and lung function impairment (Montuschi et al 2000), increasing further during exacerbations of COPD, and declining after antibiotic treatment (Biernacki et al 2003). Smoking seems to evoke an acute $50 \%$ increase in EBC 8-isoprostane levels within 15 minutes (Montuschi et al 2000). The 8-isoprostane concentrations in EBC do not correlate with age, sex, or history of smoking in pack-years (Montuschi et al 2000). No associations have been found between the levels of 8-isoprostane and dyspnea score, neutrophil count, or lung function parameters (Montuschi et al 2000).

There are still major limitations in the detection of 8-isoprostane in the $\mathrm{EBC}$, the concentrations are variable and often remain below the detection limit of the analysis (Van Hoydonck et al 2004). These limitations may be partly related to the extensive dilution that occurs from water vapour during condensation and the low concentrations to be assayed that are near the detection limits of the EIA measurements (Effros et al 2005). Other confounding factors include smoking, diurnal variation, age, alcohol consumption, caffeine and possibly also a diet rich in antioxidants. Several studies have also clearly revealed extensive variation in the levels of 8-isoprostane in nonsmokers and smokers suggesting that the commercial assay itself is variable. Based on the earlier and recent studies, it appears that EBC 8-isoprostane may not be very sensitive or specific biomarker of oxidative stress given the variability in its measurement. The actual significance of 8-isoprostane and its detection methods (eg, standardization) in the EBC still await clarification.

\section{Markers of oxidative stress in induced sputum Oxidant-generating enzymes}

The most important oxidant-generating enzymes that have been assessed in induced sputum specimens include iNOS, EPO, and MPO (Kinnula 2005b). The main location of
iNOS, which is the most efficient of the NO synthases in producing NO during inflammation, is the airway epithelium, but it has also been detected in inflammatory cells (Barnes and Belvisi 1993). Although, the levels of iNOS have been found to be elevated in the induced sputum of asthmatics (Sugiura et al 2003), variable levels of iNOS have been reported in COPD patients (Ichinose et al 2000; Rytila et al 2006). EPO is elevated in asthma while MPO, which is expressed in neutrophils and monocytes (Kim et al 2001), is elevated in COPD with the levels being higher in COPD than in asthma (Metso et al 2001). A rather similar elevation in the number of MPO-positive cells is seen in the induced sputum of chronic nonsymptomatic smokers and chronic symptomatic smokers with normal lung function, who are considered to be at risk of developing COPD (Rytila et al 2006). Sputum MPO concentrations have been reported to be extremely variable in several investigations with large standard deviations (Kim et al 2001). However, EPO and MPO may possess potential significance in differentiating asthma from COPD. MPO leads to the formation of $\mathrm{HOCl}$ and EPO to HOBr. These markers still seem to offer the greatest potential in the differentiation of asthma and COPD but both of them have been evaluated in only a few investigations. In one study, the best results when determining the most optimal fixation procedure to detect MPO and EPO in cytocentrifuged cell samples (induced sputum, BAL) were obtained using a commercial reagent Ortho PermeaFix (OPF; Ortho Clinical Diagnostics, Raritan, NJ) for flow cytometry (Metso et al 2002a). EPO was found to be a useful marker for the identification of eosinophils in sputum and bronchoalveolar lavage since anti-EPO antibodies reacted only with eosinophils (Metso et al 2002b).

\section{3-nitrotyrosine}

The reaction of $\mathrm{NO}$ and $\mathrm{O}_{2}^{--}$in the airways leads to the formation of peroxynitrite which reacts with tyrosine residues of proteins to form the stable product, nitrotyrosine (Ischiropoulos et al 1992). Nitrotyrosine can be formed not only by iNOS activation but also by MPO (Davis et al 2001). Increased nitrotyrosine immunoreactivity has been reported in the lung biopsies of asthmatics (Saleh et al 1998), in EBC from asthmatic adults (Hanazawa et al 2000) and children (Baraldi et al 2006) as described above and it is associated with asthma exacerbation. Nitrotyrosine may play a major role in the pathogenesis of airway remodelling, (Kharitonov and Barnes 2001b) and it may contribute to airway obstruction and hyperresponsiveness and epithelial damage in asthma (Saleh et al 1998). Abundant iNOS and nitrotyrosine 
positive sputum cells have also been seen in COPD patients compared to healthy smokers with a negative correlation to $\mathrm{FEV}_{1}$ (Ichinose et al 2000). However, the sputum samples of smokers without airway obstruction and also some samples of nonsmokers display increased levels of nitrotyrosine (Rytila et al 2006). It is likely that nitrotyrosine is not specific in differentiating between asthmatic and cigarette smoke-related airway disease.

\section{8-isoprostane}

Recent evidence suggests that sputum 8-isoprostane mirrors airway oxidative stress and is related to respiratory disease type pattern and activity (Wood et al 2005). The level of 8-isoprostane is higher in sputum than in EBC (Simpson et al 2005). Sputum 8-isoprostane is higher in adults with stable asthma than in healthy subjects, increase further with disease severity and decrease significantly after treatment of acute asthma exacerbation, although there is a wide variability in the 8-isoprostane concentrations between and within the groups (Wood et al 2005). Moreover, a recent study could not detect any difference between sputum 8-isoprostane levels in mild asthmatics and healthy controls (Louhelainen et al 2008). Sputum 8-isoprostane levels are elevated in COPD and cigarette smokers, but do not clearly differentiate healthy smokers from symptomatic smokers, ie, those who are at risk for developing COPD (Kinnula et al 2007). No longitudinal studies have been conducted with this marker, making it difficult to draw any final conclusions about its real significance. As described above, the major problems with this marker include the poor sensitivity, specificity and the fact that commercial EIA method and/or the impurities of the samples may contribute to its levels in sputum specimens.

\section{4-hydroxy-2-nonenal}

Aldehydes generated endogenously during lipid peroxidation may be involved in many pathophysiologic events associated with oxidative stress in cells and tissues (Gutteridge 1995). 4-HNE is a highly reactive and diffusible end-product of oxidative stress-induced lipid peroxidation that can attack targets far from the original site of free radical generation (Esterbauer et al 1991). It is hypothesized that the degree of formation of 4-HNE in response to smoking may also contribute to the development of enhanced airspace inflammation in COPD (Rahman et al 2002). 4-HNE can be detected in lung biopsies of COPD patients (Rahman et al 2002), but recently it has also been detected in induced sputum samples of chronic smokers, irrespective of the lung function parameters or symptoms compared to nonsmokers
(Rytila et al 2006). These results suggest that even though 4-HNE confirms that oxidative damage has occurred, it may not provide specific insight into the pathogenesis of the airway disease, and may not be a sensitive biomarker for assessing the disease severity.

\section{Antioxidants and antioxidant enzymes}

The oxidant/antioxidant equilibrium is disturbed in asthmatic and COPD patients not only due to the chronic inflammation, activation of inflammatory cells and/or oxidant producing enzymes but also due to changes in the antioxidant defense of the lung. It is believed that the major low molecular weight antioxidant of human airway secretions is GSH (Cantin et al 1987) but how well its levels are maintained in the ELF is still poorly understood. In addition to free GSH, a major proportion of GSH is bound to proteins and this fraction is difficult to measure. GSH has been investigated both in airway secretions and BAL but it has been shown to be neither sensitive nor specific for asthma or COPD.

The first line of defense enzymes against superoxide radicals involves superoxide dismutases (SOD) such as MnSOD and there are suggestions that MnSOD may become inactivated in the airways of asthma patients (Comhair et al 2005). Enzymes related to GSH synthesis/homeostasis such as glutathione peroxidases (GPx) play an important role in the antioxidant defense of human lung (Cantin et al 1987). Extracellular glutathione peroxidase (eGPx) has not been investigated in sputum specimens but it is increased in the BALF of asthma patients (Comhair et al 2001). Glutaredoxins (GRX) participate in GSH binding to proteins and thiol oxidation/reduction, reactions that regulate the active forms of many thiol containing enzymes. GRX-1 is mainly expressed by macrophages (Peltoniemi et al 2004) and the levels are decreased in the sputum macrophages of COPD patients (Peltoniemi et al 2006). Glutathione-S-transferase omega, which has many functional features in common with GRX, has been recently found to be expressed mainly in alveolar macrophages, and similar to GRX-1, its levels also decline in COPD (Harju et al 2007). Catalase is expressed both in the inflammatory cells and alveolar epithelium, and it is inactivated at least in the murine model of asthma (Ghosh et al 2006). Heme oxygenase 1 (HO-1) is an enzyme induced by oxidant stress (stress-response protein) and cytokines. It is expressed mainly in alveolar macrophages of human lung and macrophages of induced sputum of steroid-naïve asthmatics show prominent but only transient HO-I immunoreactivity. This is not seen in asthmatics treated with corticosteroids (Harju et al 2002b). The expression of HO-1 is increased 
also in the sputum macrophages of COPD patients compared to healthy nonsmokers, but there is no difference between COPD patients and healthy smokers (Maestrelli et al 2001). Cigarette smoking increases especially the RNA expression of GSH-related enzymes in the bronchial brushings of healthy individuals (Hackett et al 2003), but the RNA levels of antioxidant enzymes in the bronchial epithelium have high variability in COPD depending on its severity (Pierrou et al 2007). Even though the above mentioned findings have not been confirmed in sputum, the results are interesting; they suggest that combined profiles of antioxidant and detoxification enzymes and their posttranslational modifications (such as oxidation, thiolation, S-nitrosylation) may be promising indicators of the severity of oxidative stress in human airways.

\section{Matrix metalloproteinases}

Matrix metalloproteinases (MMPs) are a large family of proteolytic enzymes (over 30 MMPs have been characterized) that degrade the components of the extracellular matrix (Ohbayashi 2002). These enzymes are involved in the pulmonary remodelling processes that underpin both asthma and COPD (Parks and Shapiro 2001; Kelly and Jarjour 2003). Oxidative stress, mainly cigarette smoke associated oxidants, may be one of the major factors contributing to MMP activation. MMPs can be readily detected in sputum specimens. There are significant differences in the MMP profiles in COPD and asthma. In COPD, elevated levels of MMP-1, -8 , and -9 compared with asthmatics, nonsmokers, and nonsymptomatic cigarette smokers have been reported, and these changes may also reflect the different pathogenesis of these diseases (Culpitt et al 2005). In the future, MMPs may be considered as additional biomarkers in COPD and/or asthma development. These markers also hold potential in evaluating COPD phenotypes, since the emphysematous type of COPD would be predicted to exhibit a different profile of MMPs than the disease where there is airway predominance.

\section{Oxidant markers in bronchoalveolar lavage}

The total BAL cell profile and also the cell count differ in asthma and COPD. The number of inflammatory cells, especially neutrophils, are higher in COPD patients suffering exacerbations compared with stable COPD patients or healthy controls (Drost et al 2005). BAL fluid has been widely used for the assessment of inflammatory cytokines such as interleukin-8 (IL-8) and tumor necrosis factor alpha $(\mathrm{TNF} \alpha)$ in asthma and COPD (Aaron et al 2001;
Drost et al 2005). The most widely investigated marker of oxidant/antioxidant balance in BAL fluid is GSH, the levels of which are increased in smokers and patients with stable COPD compared to the nonsmokers, but reduced during exacerbations as compared to the levels found in stable COPD (Drost et al 2005). On the other hand, older smokers with a long-term smoking history exhibit elevated oxidized glutathione (GSSG) and protein carbonyls in their BAL fluid even in the absence of any lung disease, indicating that lung antioxidant defences have become overwhelmed the prolonged exposure to the noxious substances present in cigarette smoke (Nagai et al 2006). 8-isoprostane and some other oxidant markers have been compared between EBC and BAL, but clinical disease markers of inflammation and oxidative stress in $\mathrm{EBC}$ and BAL do not correlate with each other (Jackson et al 2007). Thus, even though some markers in BAL fluid may seem to offer promise in the assessment of inflammation, BAL is too invasive and not sensitive enough to be of use in the assessment of oxidative stress/airway inflammation in clinical practice.

\section{Pitfalls in measuring ROS in smoking asthmatics}

One problem in assessing the importance of oxidant-related biomarkers, for example FeNO and 8-isoprostane, is that smoking per se has significant effects on the levels of these markers, and this phenomenon is especially important in asthma. The prevalence of active cigarette smoking among asthmatics is as common as it is in the general population, for example in Finland as many as $30 \%$ of asthmatics are smokers (Haahtela et al 2006). There is limited data on the airway pathology of smoking asthmatics, since these patients are frequently excluded from experimental studies. Asthma and cigarette smoking potentiate the effects of each other, leading to impaired asthma control, more severe symptoms (Althuis et al 1999), increased need for rescue medication (Gallefoss and Bakke 2003), accelerated deterioration of lung function (Lange et al 1998) and reduced short-term therapeutic response to corticosteroids (Chaudhuri et al 2003). Smoking may also modify the typical asthmatic inflammation profile, which complicates the differential diagnosis from COPD. It also appears that there are features of both accelerated and suppressed inflammatory responses in smokers with asthma. The number of eosinophils in sputum are decreased (Chalmers et al 2001), perhaps due to the exogenous NO in cigarette smoke increasing apoptosis of activated eosinophils (Assreuy et al 1993) whereas the number of neutrophils is elevated (Chalmers et al 2001). Many asthmatic smokers 
have mixed features of typical asthmatic and smoke-related airway inflammation and pathology. Results from clinical studies suggest that smokers with asthma may be resistant to therapeutic effects of the corticosteroids (Chalmers et al 2001; Chaudhuri et al 2003). There is also evidence that the time of initiation of smoking may influence the asthma phenotype: atopy-associated asthma has been shown to develop before smoking initiation (Raherison et al 2003). It has been claimed that the remodeling of airways might be more severe in asthmatic smokers (Carroll et al 2000). Several markers of oxidative/nitrosative stress are increased even in "healthy" smokers, but we are not aware of any studies where the oxidant markers have been compared between healthy smokers and smoking asthmatics. It is apparent that the sensitivity of FeNO to detect a worsening of asthmatic inflammation in smokers is poor, since smoking on its own decreases FeNO levels significantly.

\section{Disease progression, COPD phenotypes, and oxidative stress}

The evaluation of oxidative stress in disease progression is especially complex in COPD. The symptoms do not closely reflect spirometric changes and the symptoms may predict exacerbation only in some individuals (Seemungal et al 2000). COPD exacerbations in turn are important events in terms of disease progression, morbidity, and mortality. Many patients with COPD never recover completely from the exacerbation. The lung pathology is especially complex in COPD as the disease contains many phenotypes displaying a wide variety of airway and emphysematous changes. However, all phenotypes are treated similarly, because there are no specific biomarkers for the differentiation of the disease subtypes or their progression. At present, no biomarker in clinical practice is able to differentiate small airway inflammation and fibrosis from alveolar destruction even though these changes are the main pathophysiologic events in COPD (Barnes et al 2006). Special efforts should be directed towards finding reliable biomarkers that would differentiate the phenotypes of COPD in addition to identifying markers that can be used in the assessment of disease progression. Though outside the scope of this review, which concentrates on local airway biomarkers, a number of biomarkers in the circulating blood/ plasma and in the skeletal muscle are under intensive investigation as ways of monitoring the progression of COPD (Aldonyte et al 2004; Gosker et al 2005; Hurst et al 2006; Jones and Agusti 2006).

Several studies have highlighted the usefulness of 8 -isoprostane in the evaluation of oxidative stress in COPD and during COPD exacerbations. This agent is known to exert biological activity such as evoking the contraction of human bronchial smooth muscle in vitro (Paredi et al 2002), and being able to elicit airway hyperresponsiveness (Held and Uhlig 2000) and evoke airway obstruction and plasma exudation (Okazawa et al 1997), evidence that it may be involved in the pathophysiology and progression of COPD. Many cross-sectional studies have shown that 8-isoprostane levels correlate with lung function parameters, but these findings have not been confirmed in longitudinal investigations. As far as we are aware there are no studies to explain how elevated 8-isoprostane levels are associated with COPD phenotypes, respond to treatment in COPD, or whether 8-isoprostane can be used in the follow-up of these patients.

Several markers of oxidant burden have been suggested to associate both with the pathogenesis and disease progression of asthma (Barnes 1990) and COPD (Repine et al 1997). Considering the complexity of oxidative stress and the inflammatory cascade and the interaction between these two processes, it is, however, unlikely that measurement of any single molecule in the EBC, sputum, or in biological fluids would be able to provide adequate information about disease progression. Potential current markers that could possibly be used for the assessment of the disease severity or progression include the combination of several markers such as EBC VOC profiles with small detectors, FeNO, sputum oxidant markers, specific MMPs, and selected antioxidant enzymes.

\section{Antioxidant therapies and disease progression}

Since it seems likely that asthma and COPD are associated with an elevated oxidant burden, these diseases might be treated with exogenous antioxidants or related strategies. It is likely that vitamins taken orally do not reach the critically damaged areas of the lung, which has its own highly specific antioxidant systems. Several attempts have been made to improve GSH homeostasis by treatment with inhaled and oral GSH, since the level of GSH is much higher in the epithelial lining fluid than in any other organ or circulating blood, and decreased by oxidative stress. However, GSH is poorly absorbed through membranes and inhaled GSH itself has been shown to cause bronchoconstriction (Rahman and MacNee 1999). N-acetyl-L-cysteine (NAC) may improve GSH balance but this compound is known to also possess GSH-independent pro-oxidant effects at the cellular level. NAC has been tested and administered by inhalation, orally and intravenously (Rahman and MacNee 1999). 
Oral NAC has been shown to decrease the risk for COPD re-hospitalisations (Gerrits et al 2003) and to decrease $\mathrm{H}_{2} \mathrm{O}_{2}$ levels in the exhaled air in COPD (Kasielski and Nowak 2001), but the results of the multicenter BRONCUS-trial revealed no major effects on lung function values or COPD exacerbations (Dekhuijzen 2004; Decramer et al 2005). A recent systematic review on NAC indicated that the use of NAC could significantly reduce the odds of exacerbation in patients with COPD (Sutherland et al 2006) and therefore could possibly have effects on disease progression. Whether the new antioxidant mimetics that are under development will have benefits in asthma or COPD will be an interesting area of future investigation.

\section{Perspective/conclusions}

The assessment of noninvasive biomarkers in asthma and COPD is an area of intensive investigation. Noninvasive specimens that reflect oxidative stress in the airways include exhaled air, EBC, and induced sputum. Induced sputum is a widely used technique and there are many advantages in using induced sputum both in asthma and COPD. One practical problem with induced sputum, however, is the fact that it is not totally noninvasive and sample processing requires expertise. Nonetheless, induced sputum is promising especially for the analysis of markers with different roles in the pathogenesis of asthma and COPD. One example is the differentiation of the subphenotypes (either airway or emphysema predominance) of COPD by combining the existent knowledge of oxidant markers in the sputum specimens and expanding the methodology to new technologies including proteomics (sputome).
Exhaled air and EBC are totally noninvasive and therefore most interesting for the clinical evaluation of airway diseases, their differential diagnosis and progression. FeNO has been the most widely used of the various markers and has been shown to have clinical significance in asthma, its differential diagnosis and monitoring (Table 1). Further emphasis should be directed in the development of small, easy-to-handle, portable devices for the investigation of the exhaled gas profiles (such as VOCs) and their role especially in COPD. Real time analysis of volatile organic molecules by infrared laser spectroscopy enables online measurement of oxidative markers (Murtz et al 1999) and these techniques offer the potential for real time monitoring of EBC also in asthma and COPD. Metabolomic analysis (quantitative measurement of the dynamic multiparametric metabolic response of living systems to pathophysiological stimuli or genetic modification) (Nicholson et al 1999) can provide new biochemical profiles for the assessment of low molecular weight metabolites in EBC. These methods include nuclear magnetic resonance (NMR) and allow simultaneous detection of hundreds of low molecular weight species within a single fluid sample. These NMR "fingerprints" may further improve the characterization of the specific features in asthma and COPD and their differentiation (Carraro et al 2007). Lipidomics has been evaluated in vitro and in the developing lung (Postle et al 2006; Bernhard et al 2007), but its value in asthma and COPD remains to be confirmed in the future.

Many investigations have used sophisticated techniques such as microarray or proteomics which generate enormous amounts of information that is difficult to interpret even

Table I The principal noninvasive methods in assessing airway inflammation and oxidative stress from patients with known or suspected obstructive pulmonary disease. The list includes some markers that already are in clinical use as well as several markers in experimental use

\begin{tabular}{|c|c|c|c|}
\hline Specimens & Advantages & Disadvantages & Markers \\
\hline Exhaled air & $\begin{array}{l}\text { Noninvasiveness, useful for } \\
\text { children, follow up of asthmatic } \\
\text { inflammation }\end{array}$ & Minor significance in COPD, & $\underline{\text { FeNO}}$, ethane, $\mathrm{H}_{2} \mathrm{O}_{2}, \mathrm{CO}$ \\
\hline Exhaled breath condensate & $\begin{array}{l}\text { Noninvasiveness, useful for } \\
\text { children }\end{array}$ & $\begin{array}{l}\text { Problems with sample dilution, } \\
\text { lack of standardization and } \\
\text { specificity }\end{array}$ & $\mathrm{H}_{2} \mathrm{O}_{2}$, 8-isoprostane, cytokines, \\
\hline Induced sputum & $\begin{array}{l}\text { Informative; inflammatory cell } \\
\text { profile }\end{array}$ & $\begin{array}{l}\text { Can cause inflammation/ } \\
\text { bronchoconstiction, requirements } \\
\text { for laboratory standards }\end{array}$ & $\begin{array}{l}\text { Inflammatory cells. EPO, ECP, } \\
\text { MPO, iNOS, Nitro-tyrosine, } \\
\text { 8-isoprostane, 4-HNE, MMPs }\end{array}$ \\
\hline Bronchoalveolar lavage fluid & Accurate, standardized method & $\begin{array}{l}\text { Invasiveness. Information is } \\
\text { obtained only from the alveolar } \\
\text { level }\end{array}$ & $\begin{array}{l}\text { Inflammatory cells and } \\
\text { selected cytokines, GSH, } \\
\text { MMPs }\end{array}$ \\
\hline
\end{tabular}

Notes: The best potential current markers in the differential diagnosis of asthma and COPD are underlined. Among all oxidant markers FeNO is widely used in clinical practice. Abbreviations: COPD, chronic obstructive pulmonary disease; FeNO, fractional exhaled nitric oxide; $\mathrm{CO}$, carbon monoxide; $\mathrm{H}_{2} \mathrm{O}_{2}$, hydrogen peroxide; $i \mathrm{NOS}$, inducible nitric oxide synthase; EPO, eosinophilic peroxidase; ECP, eosinophilic cationic protein; MPO, myeloperoxidase; 4-HNE, 4-hydroxy-2-nonenal; MMPs, matrix metalloproteinases; GSH, glutathione. 
Table 2 Potential noninvasive oxidant biomarkers for the assessment of asthma, COPD, their differential diagnosis and phenotypes by combining the existent knowledge and future technologies

\section{Exhaled air/exhaled breath condensate (EBC)}

- FeNO (various flow rates)

- Profiles/clusters of volatile compounds by using new gas chromatographic/MS technologies

- Metabolomics (Assessment of low molecular weight compounds in $\mathrm{EBC}$ )

\section{Induced sputum}

- Combinations of certain oxidant markers and footprints of oxidative damage (differential diagnosis, disease severity)

- Combinations of certain antioxidant enzymes (disease severity)

- Posttranslational modifications/inactivation of the antioxidant/ detoxification enzymes in human lung (disease severity)

- Matrix metalloproteinases and their specific combinations (disease severity, differential diagnosis, phenotype)

- Sputome (proteomics from induced sputum) (differential diagnosis, disease severity, phenotype) by the investigators. It is clearly challenging to extrapolate these results from a specific cell type (for example bronchial epithelial cells obtained by bronchial brushing) or from total lung homogenate to a noninvasive specimen such as exhaled air or sputum. It is likely that proteomics offers multiple advantages compared to the gene expression studies since proteins and not genes ultimately determine cellular function (Raj et al 2007). Proteomic studies have also revealed a total of nearly 200 human proteins from the induced sputum specimens (sputome) (Nicholas et al 2006; Casado et al 2007) and these profiles may differ in various airway diseases and phenotypes (Casado et al 2007). Recent studies have also discovered panels/clusters of oxidant/antioxidant enzymes that may be utilized for the assessment of disease severity. Overproduction of ROS can also cause oxidative modifications of several important antioxidant/defense enzymes, which may

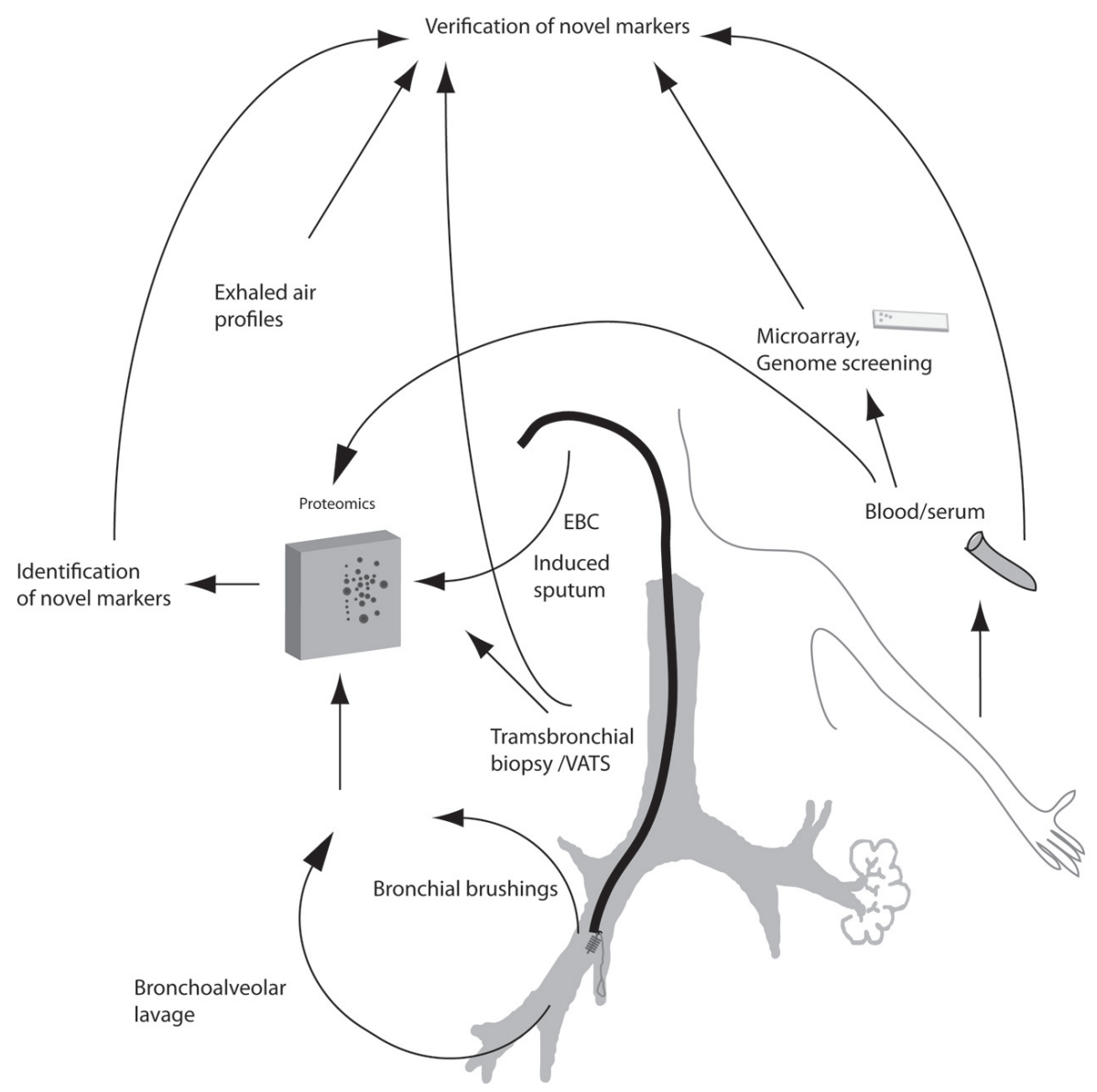

Figure 2 Future strategies for the discovery of new biomarkers in asthma and COPD, their diagnosis, differential diagnosis and assessment of the COPD phenotypes. The methods include microarray and proteomics combined with novel technologies. In these studies, protein expression has multiple advantages compared to gene expression, since proteins and not genes finally determine cellular function. Methods such as metabolomics (analysis of low molecular weight molecules from exhaled breath condensate), lipodomics and sputome (proteomics from induced sputum) have been evaluated and are ready for clinical prospective studies in asthma and COPD. Microarray/proteomics obtained from lung tissue, bronchial brushings and/or bronchoalveolar lavage have been conducted in asthma and/or COPD, and their extrapolation to noninvasive samples is being investigated in many laboratories. 
be associated with alterations in enzyme conformation and thus they can function as markers of the degree of oxidative stress present in the airways. These changes that currently can be analyzed by 2DE electrophoresis and MS but in the future new potent nongel-based proteomic methods may represent the next generation of more specific biomarkers both for asthma and COPD. In view of the overlapping patterns of the profiles of various oxidant biomarkers in asthma and COPD, the utilization of very sophisticated techniques in their assessment is important. Since cigarette smoking is inevitably related to COPD and since smoking only partly overlaps with the pathophysiology of asthma, new tools might offer an easier and cost-effective way for early diagnosis and differentiation of asthma and COPD. The future directions in the search for potential markers of oxidant burden are summarized in Table 2 and Figure 2.

\section{Acknowledgments}

This review and our studies closely related to this issue have been supported by the EVO funding of Helsinki University Hospital, Finnish Antituberculosis Association Foundation, the Ahokas Foundation, the Finnish medical foundation, and the Yrjo Jahnsson Foundation. The authors report no conflicts of interest in this work.

\section{References}

Aaron SD, Angel JB, Lunau M, et al. 2001. Granulocyte inflammatory markers and airway infection during acute exacerbation of chronic obstructive pulmonary disease. Am J Respir Crit Care Med, 163:349-55.

Aldonyte R, Eriksson S, Piitulainen E, et al. 2004. Analysis of systemic biomarkers in COPD patients. COPD, 1:155-64.

Aldridge RE, Chan T, van Dalen CJ, et al. 2002. Eosinophil peroxidase produces hypobromous acid in the airways of stable asthmatics. Free Radic Biol Med, 33:847-56.

Alexis NE, Hu SC, Zeman K, et al. 2001. Induced sputum derives from the central airways: confirmation using a radiolabeled aerosol bolus delivery technique. Am J Respir Crit Care Med, 164:1964-70.

Althuis MD, Sexton M, Prybylski D. 1999. Cigarette smoking and asthma symptom severity among adult asthmatics. J Asthma, 36:257-64.

Alving K, Weitzberg E, Lundberg JM. 1993. Increased amount of nitric oxide in exhaled air of asthmatics. Eur Respir J, 6:1368-70.

Anderson R, Theron AJ, Ras GJ. 1988. Ascorbic acid neutralizes reactive oxidants released by hyperactive phagocytes from cigarette smokers. Lung, 166:149-59.

Anonymous. 1999. Recommendations for standardized procedures for the online and offline measurement of exhaled lower respiratory nitric oxide and nasal in adults and children. Am J Respir Crit Care Med, 160:2104-17.

Antczak A, Kharitonov SA, Montuschi P, et al. 2005. Inflammatory response to sputum induction measured by exhaled markers. Respiration, 72:594-9.

Antczak A, Montuschi P, Kharitonov S, et al. 2002. Increased exhaled cysteinyl-leukotrienes and 8-isoprostane in aspirin-induced asthma. Am J Respir Crit Care Med, 166:301-6.

Assreuy J, Cunha FQ, Liew FY, et al. 1993. Feedback inhibition of nitric oxide synthase activity by nitric oxide. Br J Pharmacol, 108:833-7.
Baraldi E, Carraro S, Alinovi R, et al. 2003a. Cysteinyl leukotrienes and 8 -isoprostane in exhaled breath condensate of children with asthma exacerbations. Thorax, 58:505-9.

Baraldi E, Ghiro L, Piovan V, et al. 2003b. Increased exhaled 8-isoprostane in childhood asthma. Chest, 124:25-31.

Baraldi E, Ghiro L, Piovan V, et al. 2003c. Safety and success of exhaled breath condensate collection in asthma. Arch Dis Child, 88:358-60.

Baraldi E, Giordano G, Pasquale MF, et al. 2006. 3-Nitrotyrosine, a marker of nitrosative stress, is increased in breath condensate of allergic asthmatic children. Allergy, 61:90-6.

Barnes PJ. 1990. Reactive oxygen species and airway inflammation. Free Radic Biol Med, 9:235-43.

Barnes PJ, Belvisi MG. 1993. Nitric oxide and lung disease. Thorax, 48:1034-43.

Barnes PJ, Chowdhury B, Kharitonov SA, et al. 2006. Pulmonary biomarkers in chronic obstructive pulmonary disease. Am J Respir Crit Care Med, 174:6-14.

Battaglia S, den HH, Timmers MC, et al. 2005. Small airways function and molecular markers in exhaled air in mild asthma. Thorax, 60:639-44.

Baughman RP, Corser BC, Strohofer S, et al. 1986. Spontaneous hydrogen peroxide release from alveolar macrophages of some cigarette smokers. $J$ Lab Clin Med, 107:233-7.

Bernhard W, Schmiedl A, Koster G, et al. 2007. Developmental changes in rat surfactant lipidomics in the context of species variability. Pediatr Pulmonol, 42:794-804.

Biernacki WA, Kharitonov SA, Barnes PJ. 2003. Increased leukotriene B4 and 8-isoprostane in exhaled breath condensate of patients with exacerbations of COPD. Thorax, 58:294-8.

Bodini A, Peroni D, Vicentini L, et al. 2004. Exhaled breath condensate eicosanoids and sputum eosinophils in asthmatic children: a pilot study. Pediatr Allergy Immunol, 15:26-31.

Bodini A, Peroni DG, Zardini F, et al. 2006. Flunisolide decreases exhaled nitric oxide and nitrotyrosine levels in asthmatic children. Mediators Inflamm, 2006:31919.

Bosken CH, Hards J, Gatter K, et al. 1992. Characterization of the inflammatory reaction in the peripheral airways of cigarette smokers using immunocytochemistry. Am Rev Respir Dis, 145:911-7.

Boulet LP, Turcotte H, Hudon C, et al. 1998. Clinical, physiological and radiological features of asthma with incomplete reversibility of airflow obstruction compared with those of COPD. Can Respir $J, 5: 270-7$.

Bousquet J, Jeffery PK, Busse WW, et al. 2000. Asthma. From bronchoconstriction to airways inflammation and remodeling. Am J Respir Crit Care Med, 161:1720-45.

Brindicci C, Ito K, Resta O, et al. 2005. Exhaled nitric oxide from lung periphery is increased in COPD. Eur Respir J, 26:52-9.

Byrnes CA, Dinarevic S, Shinebourne EA, et al. 1997. Exhaled nitric oxide measurements in normal and asthmatic children. Pediatr Pulmonol, 24:312-18.

Cantin AM, North SL, Hubbard RC, et al. 1987. Normal alveolar epithelial lining fluid contains high levels of glutathione. J Appl Physiol, 63:152-7.

Carraro S, Rezzi S, Reniero F, et al. 2007. Metabolomics applied to exhaled breath condensate in childhood asthma. Am J Respir Crit Care Med, 175:986-90.

Carroll NG, Perry S, Karkhanis A, et al. 2000. The airway longitudinal elastic fiber network and mucosal folding in patients with asthma. Am J Respir Crit Care Med, 161:244-8.

Casado B, Iadarola P, Pannell LK, et al. 2007. Protein expression in sputum of smokers and chronic obstructive pulmonary disease patients: a pilot study by CapLC-ESI-Q-TOF. J Proteome Res, 6:4615-23.

Celio S, Troxler H, Durka SS, et al. 2006. Free 3-nitrotyrosine in exhaled breath condensates of children fails as a marker for oxidative stress in stable cystic fibrosis and asthma. Nitric Oxide, 15:226-32.

Chalmers GW, MacLeod KJ, Thomson L, et al. 2001. Smoking and airway inflammation in patients with mild asthma. Chest, 120:1917-22. 
Chanez P, Vignola AM, Vic P, et al. 1999. Comparison between nasal and bronchial inflammation in asthmatic and control subjects. Am J Respir Crit Care Med, 159:588-95.

Chaudhuri R, Livingston E, McMahon AD, et al. 2003. Cigarette smoking impairs the therapeutic response to oral corticosteroids in chronic asthma. Am J Respir Crit Care Med, 168:1308-11.

Church DF, Pryor WA. 1985. Free-radical chemistry of cigarette smoke and its toxicological implications. Environ Health Perspect, 64:111-26.

Comhair SA, Bhathena PR, Farver C, et al. 2001. Extracellular glutathione peroxidase induction in asthmatic lungs: evidence for redox regulation of expression in human airway epithelial cells. FASEB J, 15:70-8.

Comhair SA, Xu W, Ghosh S, et al. 2005. Superoxide dismutase inactivation in pathophysiology of asthmatic airway remodeling and reactivity. Am $J$ Pathol, 166:663-74.

Corradi M, Montuschi P, Donnelly LE, et al. 2001. Increased nitrosothiols in exhaled breath condensate in inflammatory airway diseases. Am J Respir Crit Care Med, 163:854-8.

Corradi M, Pignatti P, Manini P, et al. 2004. Comparison between exhaled and sputum oxidative stress biomarkers in chronic airway inflammation. Eur Respir J, 24:1011-7.

Cracowski JL, Durand T, Bessard G. 2002. Isoprostanes as a biomarker of lipid peroxidation in humans: physiology, pharmacology and clinical implications. Trends Pharmacol Sci, 23:360-6.

Culpitt SV, Rogers DF. 2000. Evaluation of current pharmacotherapy of chronic obstructive pulmonary disease. Expert Opin Pharmacother, $1: 1007-20$.

Culpitt SV, Rogers DF, Traves SL, et al. 2005. Sputum matrix metalloproteases: comparison between chronic obstructive pulmonary disease and asthma. Respir Med, 99:703-10.

Davis KL, Martin E, Turko IV, et al. 2001. Novel effects of nitric oxide. Annu Rev Pharmacol Toxicol, 41:203-36.

Decramer M, Rutten-van MM, Dekhuijzen PN, et al. 2005. Effects of $\mathrm{N}$-acetylcysteine on outcomes in chronic obstructive pulmonary disease (Bronchitis Randomized on NAC Cost-Utility Study, BRONCUS): a randomised placebo-controlled trial. Lancet, 365:1552-60.

Dekhuijzen PN. 2004. Antioxidant properties of N-acetylcysteine: their relevance in relation to chronic obstructive pulmonary disease. Eur Respir J, 23:629-36.

Dekhuijzen PN, Aben KK, Dekker I, et al. 1996. Increased exhalation of hydrogen peroxide in patients with stable and unstable chronic obstructive pulmonary disease. Am J Respir Crit Care Med, 154:813-6.

Djukanovic R, Sterk PJ, Fahy JV, et al. 2002. Standardised methodology of sputum induction and processing. Eur Respir J Suppl, 37:1s-55s.

Dragonieri S, Schot R, Mertens BJ, et al. 2007. An electronic nose in the discrimination of patients with asthma and controls. J Allergy Clin Immunol, 120:856-62.

Drost EM, Skwarski KM, Sauleda J, et al. 2005. Oxidative stress and airway inflammation in severe exacerbations of COPD. Thorax, 60:293-300.

Dworski R. 2000. Oxidant stress in asthma. Thorax, 55 Suppl 2:S51-S53.

Effros RM, Su J, Casaburi R, et al. 2005. Utility of exhaled breath condensates in chronic obstructive pulmonary disease: a critical review. Curr Opin Pulm Med, 11:135-9.

Esterbauer H, Schaur RJ, Zollner H. 1991. Chemistry and biochemistry of 4-hydroxynonenal, malonaldehyde and related aldehydes. Free Radic Biol Med, 11:81-128.

Fabbri LM, Romagnoli M, Corbetta L, et al. 2003. Differences in airway inflammation in patients with fixed airflow obstruction due to asthma or chronic obstructive pulmonary disease. Am J Respir Crit Care Med, 167:418-24.

Fahy JV, Boushey HA, Lazarus SC, et al. 2001. Safety and reproducibility of sputum induction in asthmatic subjects in a multicenter study. Am J Respir Crit Care Med, 163:1470-5.

Fahy JV, Kim KW, Liu J, et al. 1995a. Prominent neutrophilic inflammation in sputum from subjects with asthma exacerbation. J Allergy Clin Immunol, 95:843-52.
Fahy JV, Wong H, Liu J, et al. 1995b. Comparison of samples collected by sputum induction and bronchoscopy from asthmatic and healthy subjects. Am J Respir Crit Care Med, 152:53-8.

Fletcher C, Peto R. 1977. The natural history of chronic airflow obstruction. Br Med $J, 1: 1645-8$.

Franklin P, Moeller A, Hall GL, et al. 2006. Variability of nitric oxide metabolites in exhaled breath condensate. Respir Med, 100:123-9.

Gallefoss F, Bakke PS. 2003. Does smoking affect the outcome of patient education and self-management in asthmatics? Patient Educ Couns, 49:91-7.

Gerrits CM, Herings RM, Leufkens HG, et al. 2003. N-acetylcysteine reduces the risk of re-hospitalisation among patients with chronic obstructive pulmonary disease. Eur Respir J, 21:795-8.

[GINA] Global Initiative for Asthma. 2002. Global strategies for asthma management and prevention. National Institutes of Health, National Heart, Lung and Blood Institute. [online]. NIH Publication, No 02-3659. Accessed on December 12, 2007. URL: http://www.ginasthma.com.

Ghosh S, Janocha AJ, Aronica MA, et al. 2006. Nitrotyrosine proteome survey in asthma identifies oxidative mechanism of catalase inactivation. J Immunol, 176:5587-97.

Gibson PG, Norzila MZ, Fakes K, et al. 1999. Pattern of airway inflammation and its determinants in children with acute severe asthma. Pediatr Pulmonol, 28:261-70.

[GOLD] Global Initiative for Chronic Obstructive Lung Disease. 2002. Global initiative for chronic obstructive lung disease. Global strategy for the diagnosis, management and prevention of chronic obstructive pulmonary disease NHLBI/WHO Workshop Report [online]. NIH Publication, No 2701, Accessed on December 12, 2007. URL: http:// www.goldcopd.com.

Gompertz S, Bayley DL, Hill SL, et al. 2001. Relationship between airway inflammation and the frequency of exacerbations in patients with smoking related COPD. Thorax, 56:36-41.

Gopaul NK, Halliwell B, Anggard EE. 2000. Measurement of plasma F2-isoprostanes as an index of lipid peroxidation does not appear to be confounded by diet. Free Radic Res, 33:115-27.

Gosker HR, Bast A, Haenen GR, et al. 2005. Altered antioxidant status in peripheral skeletal muscle of patients with COPD. Respir Med, 99:118-25.

Guatura SB, Martinez JA, Santos Bueno PC, et al. 2000. Increased exhalation of hydrogen peroxide in healthy subjects following cigarette consumption. Sao Paulo Med J, 118:93-8.

Gutteridge JM. 1995. Lipid peroxidation and antioxidants as biomarkers of tissue damage. Clin Chem, 41:1819-28.

Haahtela T, Tuomisto LE, Pietinalho A, et al. 2006. A 10 year asthma programme in Finland: major change for the better. Thorax, 61:663-70

Habib MP, Clements NC, Garewal HS. 1995. Cigarette smoking and ethane exhalation in humans. Am J Respir Crit Care Med, 151:1368-72.

Habib MP, Tank LJ, Lane LC, et al. 1999. Effect of vitamin E on exhaled ethane in cigarette smokers. Chest, 115:684-90.

Hackett NR, Heguy A, Harvey BG, et al. 2003. Variability of antioxidantrelated gene expression in the airway epithelium of cigarette smokers. Am J Respir Cell Mol Biol, 29:331-43.

Hamid Q, Song Y, Kotsimbos TC, et al. 1997. Inflammation of small airways in asthma. J Allergy Clin Immunol, 100:44-51.

Hanazawa T, Kharitonov SA, Barnes PJ. 2000. Increased nitrotyrosine in exhaled breath condensate of patients with asthma. Am J Respir Crit Care Med, 162:1273-6.

Harju T, Kaarteenaho-Wiik R, Soini Y, et al. 2002a. Diminished immunoreactivity of gamma-glutamylcysteine synthetase in the airways of smokers' lung. Am J Respir Crit Care Med, 166:754-9.

Harju T, Soini Y, Paakko R, et al. 2002b. Up-regulation of heme oxygenase-I in alveolar macrophages of newly diagnosed asthmatics. Respir Med, 96:418-23.

Harju TH, Peltoniemi MJ, Rytila PH, et al. 2007. Glutathione S-transferase omega in the lung and sputum supernatants of COPD patients. Respir Res, 8:48. 
Haslam PL, Baughman RP. 1999. Report of ERS Task Force: guidelines for measurement of acellular components and standardization of BAL. Eur Respir J, 14:245-8.

Hattotuwa K, Gamble EA, O'Shaughnessy T, et al. 2002. Safety of bronchoscopy, biopsy, and BAL in research patients with COPD. Chest, 122:1909-12.

Held HD, Uhlig S. 2000. Mechanisms of endotoxin-induced airway and pulmonary vascular hyperreactivity in mice. Am J Respir Crit Care Med, 162:1547-52.

Ho LP, Wood FT, Robson A, et al. 2000. Atopy influences exhaled nitric oxide levels in adult asthmatics. Chest, 118:1327-31.

Hoidal JR, Niewoehner DE. 1982. Lung phagocyte recruitment and metabolic alterations induced by cigarette smoke in humans and in hamsters. Am Rev Respir Dis, 126:548-52.

Holz O, Richter K, Jorres RA, et al. 1998. Changes in sputum composition between two inductions performed on consecutive days. Thorax, 53:83-6.

Horvath I, Donnelly LE, Kiss A, et al. 2004. Exhaled nitric oxide and hydrogen peroxide concentrations in asthmatic smokers. Respiration, 71:463-8.

Horvath I, Donnelly LE, Kiss A, et al. 1998. Raised levels of exhaled carbon monoxide are associated with an increased expression of heme oxygenase-1 in airway macrophages in asthma: a new marker of oxidative stress. Thorax, 53:668-72.

Horvath I, Hunt J, Barnes PJ, et al. 2005. Exhaled breath condensate: methodological recommendations and unresolved questions. Eur Respir J, 26:523-48.

Hurst JR, Donaldson GC, Perera WR, et al. 2006. Use of plasma biomarkers at exacerbation of chronic obstructive pulmonary disease. Am J Respir Crit Care Med, 174:867-74.

Ichinose M, Sugiura H, Yamagata S, et al. 2000. Increase in reactive nitrogen species production in chronic obstructive pulmonary disease airways. Am J Respir Crit Care Med, 162:701-6.

Ischiropoulos H, Zhu L, Chen J, et al. 1992. Peroxynitrite-mediated tyrosine nitration catalyzed by superoxide dismutase. Arch Biochem Biophys, 298:431-7.

Jackson AS, Sandrini A, Campbell C, et al. 2007. Comparison of biomarkers in exhaled breath condensate and bronchoalveolar lavage. Am J Respir Crit Care Med, 175:222-7.

Janssen LJ. 2001. Isoprostanes: an overview and putative roles in pulmonary pathophysiology. Am J Physiol Lung Cell Mol Physiol, 280: L1067-L1082.

Jatakanon A, Lim S, Barnes PJ. 2000. Changes in sputum eosinophils predict loss of asthma control. Am J Respir Crit Care Med, 161:64-72.

Jeffery PK. 1999. Differences and similarities between chronic obstructive pulmonary disease and asthma. Clin Exp Allergy, 29(Suppl 2):14-26.

Jones PW, Agusti AG. 2006. Outcomes and markers in the assessment of chronic obstructive pulmonary disease. Eur Respir J, 27:822-32.

Jones RD, Hancock JT, Morice AH. 2000. NADPH oxidase: a universal oxygen sensor? Free Radic Biol Med, 29:416-24.

Kasielski M, Nowak D. 2001. Long-term administration of N-acetylcysteine decreases hydrogen peroxide exhalation in subjects with chronic obstructive pulmonary disease. Respir Med, 95:448-56.

Kawikova I, Barnes PJ, Takahashi T, et al. 1996. 8-Epi-PGF2 alpha, a novel noncyclooxygenase-derived prostaglandin, constricts airways in vitro. Am J Respir Crit Care Med, 153:590-6.

Keatings VM, Barnes PJ. 1997. Granulocyte activation markers in induced sputum: comparison between chronic obstructive pulmonary disease, asthma, and normal subjects. Am J Respir Crit Care Med, 155:449-53.

Kelly CA, Kotre CJ, Ward C, et al. 1987. Anatomical distribution of bronchoalveolar lavage fluid as assessed by digital subtraction radiography. Thorax, 42:624-8.

Kelly EA, Jarjour NN. 2003. Role of matrix metalloproteinases in asthma. Curr Opin Pulm Med, 9:28-33.
Kelly FJ, Mudway I, Blomberg A, et al. 1999. Altered lung antioxidant status in patients with mild asthma. Lancet, 354:482-3.

Kharitonov SA, Alving K, Barnes PJ. 1997. Exhaled and nasal nitric oxide measurements: recommendations. Eur Respir J, 10:1683-93.

Kharitonov SA. 2004. Exhaled markers of inflammatory lung diseases: ready for routine monitoring? Swiss Med Wkly, 134:175-92.

Kharitonov SA, Barnes PJ. 2000. Clinical aspects of exhaled nitric oxide. Eur Respir J, 16:781-92.

Kharitonov SA, Barnes PJ. 2002. Biomarkers of some pulmonary diseases in exhaled breath. Biomarkers, 7:1-32.

Kharitonov SA, Barnes PJ. 2001b. Exhaled markers of pulmonary disease. Am J Respir Crit Care Med, 163:1693-722.

Kharitonov SA, Barnes PJ. 2001a. Does exhaled nitric oxide reflect asthma control? Yes, it does! Am J Respir Crit Care Med, 164:727-8.

Kharitonov SA, Chung KF, Evans D, et al. 1996a. Increased exhaled nitric oxide in asthma is mainly derived from the lower respiratory tract. $\mathrm{Am}$ J Respir Crit Care Med, 153:1773-80.

Kharitonov SA, Donnelly LE, Montuschi P, et al. 2002. Dose-dependent onset and cessation of action of inhaled budesonide on exhaled nitric oxide and symptoms in mild asthma. Thorax, 57:889-96.

Kharitonov SA, Gonio F, Kelly C, et al. 2003. Reproducibility of exhaled nitric oxide measurements in healthy and asthmatic adults and children. Eur Respir J, 21:433-8.

Kharitonov SA, Robbins RA, Yates D, et al. 1995. Acute and chronic effects of cigarette smoking on exhaled nitric oxide. Am J Respir Crit Care Med, 152:609-12.

Kharitonov SA, Yates D, Robbins RA, et al. 1994. Increased nitric oxide in exhaled air of asthmatic patients. Lancet, 343:133-5.

Kharitonov SA, Yates DH, Chung KF, et al. 1996b. Changes in the dose of inhaled steroid affect exhaled nitric oxide levels in asthmatic patients. Eur Respir J, 9:196-201.

Kim CK, Chung CY, Choi SJ, et al. 2000. Bronchoalveolar lavage cellular composition in acute asthma and acute bronchiolitis. J Pediatr, 137:517-22.

Kim JS, Hackley GH, Okamoto K, et al. 2001. Sputum processing for evaluation of inflammatory mediators. Pediatr Pulmonol, 32:152-8.

Kinnula VL. 2005a. Focus on antioxidant enzymes and antioxidant strategies in smoking related airway diseases. Thorax, 60:693-700.

Kinnula VL. 2005b. Production and degradation of oxygen metabolites during inflammatory states in the human lung. Curr Drug Targets Inflamm Allergy, 4:465-70.

Kinnula VL, Crapo JD. 2003. Superoxide dismutases in the lung and human lung diseases. Am J Respir Crit Care Med, 167:1600-19.

Kinnula VL, Crapo JD, Raivio KO. 1995. Generation and disposal of reactive oxygen metabolites in the lung. Lab Invest, 73:3-19.

Kinnula VL, Ilumets H, Myllarniemi M, et al. 2007. 8-Isoprostane as a marker of oxidative stress in nonsymptomatic cigarette smokers and COPD. Eur Respir J, 29:51-5.

Kirby JG, Hargreave FE, Gleich GJ, et al. 1987. Bronchoalveolar cell profiles of asthmatic and nonasthmatic subjects. Am Rev Respir Dis, 136:379-83.

Kneepkens CM, Lepage G, Roy CC. 1994. The potential of the hydrocarbon breath test as a measure of lipid peroxidation. Free Radic Biol Med, 17:127-60.

Ko FW, Lau CY, Leung TF, et al. 2006. Exhaled breath condensate levels of 8-isoprostane, growth related oncogene alpha and monocyte chemoattractant protein-1 in patients with chronic obstructive pulmonary disease. Respir Med, 100:630-8.

Kostikas K, Papatheodorou G, Psathakis K, et al. 2003. Oxidative stress in expired breath condensate of patients with COPD. Chest, 124:1373-80.

Lange P, Parner J, Vestbo J, et al. 1998. A 15-year follow-up study of ventilatory function in adults with asthma. $N \mathrm{Engl} \mathrm{J} \mathrm{Med,}$ 339:1194-200.

Larstad M, Loh C, Ljungkvist G, et al. 2002. Determination of ethane, pentane and isoprene in exhaled air using a multi-bed adsorbent and end-cut gas-solid chromatography. Analyst, 127:1440-5. 
Leaf DA, Kleinman MT, Hamilton M, et al. 1997. The effect of exercise intensity on lipid peroxidation. Med Sci Sports Exerc, 29:1036-9.

Leuppi JD, Salome CM, Jenkins CR, et al. 2001. Predictive markers of asthma exacerbation during stepwise dose reduction of inhaled corticosteroids. Am J Respir Crit Care Med, 163:406-12.

Liu J, Thomas PS. 2005. Exhaled breath condensate as a method of sampling airway nitric oxide and other markers of inflammation. Med Sci Monit, 11:MT53-MT62.

Loh LC, Kanabar V, D'Amato M, et al. 2005. Sputum induction in corticosteroid-dependant asthmatics: risks and airway cellular profile. Asian Pac J Allergy Immunol, 23:189-96.

Louhelainen N, Rytila P, Obase Y, et al. 2008. The value of sputum 8 -isoprostane in detecting oxidative stress in mild asthma. $J$ Asthma, 45:149-54.

Lundberg JO, Nordvall SL, Weitzberg E, et al. 1996. Exhaled nitric oxide in paediatric asthma and cystic fibrosis. Arch Dis Child, 75:323-6.

Maestrelli P, El Messlemani AH, De FO, et al. 2001. Increased expression of heme oxygenase (HO)-1 in alveolar spaces and HO-2 in alveolar walls of smokers. Am J Respir Crit Care Med, 164:1508-13.

Maziak W, Loukides S, Culpitt S, et al. 1998. Exhaled nitric oxide in chronic obstructive pulmonary disease. Am J Respir Crit Care Med, 157:998-1002.

Metso T, Haahtela T, Seveus L. 2002a. Identification of intracellular markers in induced sputum and bronchoalveolar lavage samples in patients with respiratory disorders and healthy persons. Respir Med, 96:918-26.

Metso T, Rytila P, Peterson C, et al. 2001. Granulocyte markers in induced sputum in patients with respiratory disorders and healthy persons obtained by two sputum-processing methods. Respir Med, 95:48-55.

Metso T, Venge P, Haahtela T, et al. 2002b. Cell specific markers for eosinophils and neutrophils in sputum and bronchoalveolar lavage fluid of patients with respiratory conditions and healthy subjects. Thorax, 57:449-51.

Mondino C, Ciabattoni G, Koch P, et al. 2004. Effects of inhaled corticosteroids on exhaled leukotrienes and prostanoids in asthmatic children. $J$ Allergy Clin Immunol, 114:761-7.

Montuschi P, Barnes PJ, Roberts LJ. 2004. Isoprostanes: markers and mediators of oxidative stress. FASEB J, 18:1791-800.

Montuschi P, Collins JV, Ciabattoni G, et al. 2000. Exhaled 8-isoprostane as an in vivo biomarker of lung oxidative stress in patients with COPD and healthy smokers. Am J Respir Crit Care Med, 162:1175-7.

Montuschi P, Corradi M, Ciabattoni G, et al. 1999. Increased 8-isoprostane, a marker of oxidative stress, in exhaled condensate of asthma patients. Am J Respir Crit Care Med, 160:216-20.

Morrow JD, Hill KE, Burk RF, et al. 1990. A series of prostaglandin F2-like compounds are produced in vivo in humans by a non-cyclooxygenase, free radical-catalyzed mechanism. Proc Natl Acad Sci USA, 87:9383-7.

Morrow JD, Roberts LJ. 2002. The isoprostanes: their role as an index of oxidant stress status in human pulmonary disease. Am J Respir Crit Care Med, 166:S25-S30.

Murtz M, Frech B, Urban W. 1999. High-resolution cavity leak-out absorption spectroscopy in the 10-ìm region. App Phys, 68:243-9.

Nagai K, Betsuyaku T, Kondo T, et al. 2006. Long term smoking with age builds up excessive oxidative stress in bronchoalveolar lavage fluid. Thorax, 61:496-502.

Nathan C, Xie QW. 1994. Regulation of biosynthesis of nitric oxide. J Biol Chem, 269:13725-8.

Nelson BV, Sears S, Woods J, et al. 1997. Expired nitric oxide as a marker for childhood asthma. $J$ Pediatr, 130:423-7.

[NHLBI/WHO] National Heart, Lung and Blood Institute; World Health Organization. 2002. Global strategy for asthma management and prevention. Workshop Report. Publication No 02-3659.

Nicholas B, Skipp P, Mould R, et al. 2006. Shotgun proteomic analysis of human-induced sputum. Proteomics, 6:4390-401.

Nicholson JK, Lindon JC, Holmes E. 1999. 'Metabonomics': understanding the metabolic responses of living systems to pathophysiological stimuli via multivariate statistical analysis of biological NMR spectroscopic data. Xenobiotica, 29:1181-9.
Niewoehner DE, Kleinerman J, Rice DB. 1974. Pathologic changes in the peripheral airways of young cigarette smokers. $N$ Engl $J$ Med, 291:755-8.

Nightingale JA, Rogers DF, Barnes PJ. 1998. Effect of repeated sputum induction on cell counts in normal volunteers. Thorax, 53:87-90.

Norzila MZ, Fakes K, Henry RL, et al. 2000. Interleukin-8 secretion and neutrophil recruitment accompanies induced sputum eosinophil activation in children with acute asthma. Am J Respir Crit Care Med, 161:769-74.

Nowak D, Antczak A, Krol M, et al. 1996. Increased content of hydrogen peroxide in the expired breath of cigarette smokers. Eur Respir $J$, 9:652-7.

Ohbayashi H. 2002. Matrix metalloproteinases in lung diseases. Curr Protein Pept Sci, 3:409-21.

Okazawa A, Kawikova I, Cui ZH, et al. 1997. 8-Epi-PGF2alpha induces airflow obstruction and airway plasma exudation in vivo. Am J Respir Crit Care Med, 155:436-41.

Paggiaro PL, Chanez P, Holz O, et al. 2002. Sputum induction. Eur Respir J Suppl, 37:3s-8s.

Papi A, Romagnoli M, Baraldo S, et al. 2000. Partial reversibility of airflow limitation and increased exhaled NO and sputum eosinophilia in chronic obstructive pulmonary disease. Am J Respir Crit Care Med, 162:1773-7.

Paredi P, Kharitonov SA, Barnes PJ. 2002. Analysis of expired air for oxidation products. Am J Respir Crit Care Med, 166:S31-S37.

Paredi P, Kharitonov SA, Barnes PJ. 2000a. Elevation of exhaled ethane concentration in asthma. Am J Respir Crit Care Med, 162:1450-4.

Paredi P, Kharitonov SA, Leak D, et al. 2000b. Exhaled ethane, a marker of lipid peroxidation, is elevated in chronic obstructive pulmonary disease. Am J Respir Crit Care Med, 162:369-73.

Parks WC, Shapiro SD. 2001. Matrix metalloproteinases in lung biology. Respir Res, 2:10-9.

Peltoniemi M, Kaarteenaho-Wiik R, Saily M, et al. 2004. Expression of glutaredoxin is highly cell specific in human lung and is decreased by transforming growth factor-beta in vitro and in interstitial lung diseases in vivo. Hum Pathol, 35:1000-7.

Peltoniemi MJ, Rytila PH, Harju TH, et al. 2006. Modulation of glutaredoxin in the lung and sputum of cigarette smokers and chronic obstructive pulmonary disease. Respir Res, 7:133.

Persson MG, Zetterstrom O, Agrenius V, et al. 1994. Single-breath nitric oxide measurements in asthmatic patients and smokers. Lancet, 343:146-7.

Pierrou S, Broberg P, O’Donnell RA, et al. 2007. Expression of genes involved in oxidative stress responses in airway epithelial cells of smokers with chronic obstructive pulmonary disease. Am J Respir Crit Care Med, 175:577-86.

Pizzichini E, Pizzichini MM, Efthimiadis A, et al. 1996. Indices of airway inflammation in induced sputum: reproducibility and validity of cell and fluid-phase measurements. Am J Respir Crit Care Med, 154:308-17.

Pizzichini MM, Pizzichini E, Efthimiadis A, et al. 1998. Asthma and natural colds. Inflammatory indices in induced sputum: a feasibility study. $\mathrm{Am}$ J Respir Crit Care Med, 158:1178-84.

Postle AD, Gonzales LW, Bernhard W, et al. 2006. Lipidomics of cellular and secreted phospholipids from differentiated human fetal type II alveolar epithelial cells. J Lipid Res, 47:1322-31.

Rabe KF, Hurd S, Anzueto A, et al. 2007. Global strategy for the diagnosis, management, and prevention of chronic obstructive pulmonary disease: GOLD executive summary. Am J Respir Crit Care Med, 176:532-55.

Raherison C, Baldi I, Tunon-De-Lara JM, et al. 2003. Asthma phenotypes according to the timing of smoking onset in young adults. Int $J$ Tuberc Lung Dis, 7:84-92.

Rahman I. 2004. Reproducibility of oxidative stress biomarkers in breath condensate: are they reliable? Eur Respir J, 23:183-4.

Rahman I, Adcock IM. 2006. Oxidative stress and redox regulation of lung inflammation in COPD. Eur Respir J, 28:219-42.

Rahman I, Biswas SK. 2004. Non-invasive biomarkers of oxidative stress: reproducibility and methodological issues. Redox Rep, 9:125-43. 
Rahman I, MacNee W. 1999. Lung glutathione and oxidative stress: implications in cigarette smoke-induced airway disease. Am J Physiol, 277: L1067-L1088.

Rahman I, MacNee W. 2000. Oxidative stress and regulation of glutathione in lung inflammation. Eur Respir J, 16:534-54.

Rahman I, MacNee W. 1998. Role of transcription factors in inflammatory lung diseases. Thorax, 53:601-12.

Rahman I, Morrison D, Donaldson K, et al. 1996. Systemic oxidative stress in asthma, COPD, and smokers. Am J Respir Crit Care Med, 154:1055-60.

Rahman I, van Schadewijk AA, Crowther AJ, et al. 2002. 4-Hydroxy-2nonenal, a specific lipid peroxidation product, is elevated in lungs of patients with chronic obstructive pulmonary disease. Am J Respir Crit Care Med, 166:490-5.

Raj JU, Aliferis C, Caprioli RM, et al. 2007. Genomics and proteomics of lung disease: conference summary. Am J Physiol Lung Cell Mol Physiol, 293:L45-L51.

Repine JE, Bast A, Lankhorst I. 1997. Oxidative stress in chronic obstructive pulmonary disease. Oxidative Stress Study Group. Am J Respir Crit Care Med, 156:341-57.

Robbins RA, Floreani AA, Von Essen SG, et al. 1996. Measurement of exhaled nitric oxide by three different techniques. Am J Respir Crit Care Med, 153:1631-5.

Rytila P, Rehn T, Ilumets H, et al. 2006. Increased oxidative stress in asymptomatic current chronic smokers and GOLD stage 0 COPD. Respir Res, 7:69.

Rytila PH, Lindqvist AE, Laitinen LA. 2000. Safety of sputum induction in chronic obstructive pulmonary disease. Eur Respir J, 15:1116-9.

Saetta M. 1999. Airway inflammation in chronic obstructive pulmonary disease. Am J Respir Crit Care Med, 160:S17-S20.

Saetta M, Turato G, Maestrelli P, et al. 2001. Cellular and structural bases of chronic obstructive pulmonary disease. Am J Respir Crit Care Med, 163:1304-9.

Saleh D, Ernst P, Lim S, et al. 1998. Increased formation of the potent oxidant peroxynitrite in the airways of asthmatic patients is associated with induction of nitric oxide synthase: effect of inhaled glucocorticoid. FASEB J, 12:929-37.

Scanlon PD, Connett JE, Waller LA, et al. 2000. Smoking cessation and lung function in mild-to-moderate chronic obstructive pulmonary disease The Lung Health Study. Am J Respir Crit Care Med, 161:381-90.

Seemungal TA, Donaldson GC, Bhowmik A, et al. 2000. Time course and recovery of exacerbations in patients with chronic obstructive pulmonary disease. Am J Respir Crit Care Med, 161:1608-13.

Shahid SK, Kharitonov SA, Wilson NM, et al. 2005. Exhaled 8-isoprostane in childhood asthma. Respir Res, 6:79.

Silvestri M, Spallarossa D, Frangova Yourukova V, et al. 1999. Orally exhaled nitric oxide levels are related to the degree of blood eosinophilia in atopic children with mild-intermittent asthma. Eur Respir J, 13:321-6.

Simpson JL, Timmins NL, Fakes K, et al. 2004. Effect of saliva contamination on induced sputum cell counts, IL-8 and eosinophil cationic protein levels. Eur Respir J, 23:759-62.

Simpson JL, Wood LG, Gibson PG. 2005. Inflammatory mediators in exhaled breath, induced sputum and saliva. Clin Exp Allergy, 35:1180-5.

Sippel JM, Holden WE, Tilles SA, et al. 2000. Exhaled nitric oxide levels correlate with measures of disease control in asthma. J Allergy Clin Immunol, 106:645-50
Smith AD, Cowan JO, Brassett KP, et al. 2005. Use of exhaled nitric oxide measurements to guide treatment in chronic asthma. $N$ Engl J Med, 352:2163-73.

Smith CM, Anderson SD. 1990. Inhalational challenge using hypertonic saline in asthmatic subjects: a comparison with responses to hyperpnoea, methacholine and water. Eur Respir J, 3:144-51.

Su Y, Han W, Giraldo C, et al. 1998. Effect of cigarette smoke extract on nitric oxide synthase in pulmonary artery endothelial cells. Am J Respir Cell Mol Biol, 19:819-25.

Sugiura H, Ichinose M, Yamagata S, et al. 2003. Correlation between change in pulmonary function and suppression of reactive nitrogen species production following steroid treatment in COPD. Thorax, 58:299-305.

Sutherland ER, Crapo JD, Bowler RP. 2006. N-acetylcysteine and exacerbations of chronic obstructive pulmonary disease. COPD, 3:195-202.

Taube C, Holz O, Mucke M, et al. 2001. Airway response to inhaled hypertonic saline in patients with moderate to severe chronic obstructive pulmonary disease. Am J Respir Crit Care Med, 164:1810-5.

Tetley TD. 2005. Inflammatory cells and chronic obstructive pulmonary disease. Curr Drug Targets Inflamm Allergy, 4:607-18.

Twaddell SH, Gibson PG, Carty K, et al. 1996. Assessment of airway inflammation in children with acute asthma using induced sputum. Eur Respir J, 9:2104-8.

van Aalderen WM, Sprikkelman AB, Hoekstra MO. 1999. Is childhood asthma an inflammatory disease? Allergy, 54 (Suppl 49):62-7.

van Beurden WJ, Harff GA, Dekhuijzen PN, et al. 2002. An efficient and reproducible method for measuring hydrogen peroxide in exhaled breath condensate. Respir Med, 96:197-203.

van Dalen CJ, Kettle AJ. 2001. Substrates and products of eosinophil peroxidase. Biochem J, 358:233-9.

Van Hoydonck PG, Wuyts WA, Vanaudenaerde BM, et al. 2004. Quantitative analysis of 8-isoprostane and hydrogen peroxide in exhaled breath condensate. Eur Respir J, 23:189-92.

Vlachos-Mayer H, Leigh R, Sharon RF, et al. 2000. Success and safety of sputum induction in the clinical setting. Eur Respir J, 16:997-1000.

Walters EH, Gardiner PV. 1992. Bronchoalveolar lavage findings and bronchial hyperreactivity. Respiration, 59(Suppl 1):6-8.

Ward R, Woltmann G, Wardlaw AJ, et al. 1999. Between-observer repeatability of sputum differential cell counts. Influence of cell viability and squamous cell contamination. Clin Exp Allergy, 29:248-52.

Wark PA, Johnston SL, Moric I, et al. 2002. Neutrophil degranulation and cell lysis is associated with clinical severity in virus-induced asthma. Eur Respir J, 19:68-75.

Wark PA, Simpson JL, Hensley MJ, et al. 2001. Safety of sputum induction with isotonic saline in adults with acute severe asthma. Clin Exp Allergy, 31:1745-53.

Wilson AM, Leigh R, Hargreave FE, et al. 2006. Safety of sputum induction in moderate-to-severe smoking-related chronic obstructive pulmonary disease. COPD, 3:89-93.

Wood LG, Gibson PG, Garg ML. 2003. Biomarkers of lipid peroxidation, airway inflammation and asthma. Eur Respir J, 21:177-86.

Wood LG, Garg ML, Simpson JL, et al. 2005. Induced sputum 8-isoprostane concentrations in inflammatory airway diseases. Am J Respir Crit Care Med, 171:426-30.

Wu W, Samoszuk MK, Comhair SA, et al. 2000. Eosinophils generate brominating oxidants in allergen-induced asthma. J Clin Invest, 105:1455-63.

Zayasu K, Sekizawa K, Okinaga S, et al. 1997. Increased carbon monoxide in exhaled air of asthmatic patients. Am J Respir Crit Care Med, 156:1140-3. 
